\title{
Modular cell-free expression plasmids to accelerate biological design in cells
}

Ashty S. Karim ${ }^{1,2,3, \#}$, Fungmin (Eric) Liew ${ }^{4, \#}$, Shivani Garg ${ }^{4}$, Bastian Vögeli ${ }^{1,2,3}$, Blake J.

Rasor $^{1,2,3}$, Aislinn Gonnot ${ }^{4}$, Marilene Pavan ${ }^{4}$, Alex Juminaga ${ }^{4}$, Séan D. Simpson ${ }^{4}$, Michael

Köpke $^{4, *}$, Michael C. Jewett ${ }^{1,2,3,5, *}$

${ }^{1}$ Department of Chemical and Biological Engineering, Northwestern University, Evanston, IL 60208, USA

${ }^{2}$ Chemistry of Life Processes Institute, Northwestern University, Evanston, IL 60208, USA

${ }^{3}$ Center for Synthetic Biology, Northwestern University, Evanston, IL 60208, USA

${ }^{4}$ LanzaTech Inc., 8045 Lamon Ave Suite 400, Skokie, IL 60077, USA

${ }^{5}$ Simpson Querrey Institute, Northwestern University, Chicago, IL 60611, USA

\#These authors contributed equally to this work

*Corresponding Authors: Michael C. Jewett, m-jewett@northwestern.edu and Michael Köpke, Michael.Koepke@lanzatech.com 


\section{Abstract}

Industrial biotechnology aims to produce high-value products from renewable resources. This can be challenging because model microorganisms-organisms that are easy to use like Escherichia coli-often lack the machinery required to utilize desired feedstocks like lignocellulosic biomass or syngas. Non-model organisms, such as Clostridium, are industrially proven and have the desired metabolic features but have several hurdles to mainstream use. Namely, these species grow more slowly than conventional laboratory microbes and genetic tools for engineering them are far less prevalent. To address these hurdles for accelerating cellular design, cell-free synthetic biology has emerged as an approach for characterizing non-model organisms and rapidly testing metabolic pathways in vitro. Unfortunately, cell-free systems can require specialized DNA architectures with minimal regulation that are not compatible with cellular expression. In this work, we develop a modular vector system that allows for T7 expression of desired enzymes for cell-free expression and direct Golden Gate assembly into Clostridium expression vectors. Utilizing the Joint Genome Institute's DNA Synthesis Community Science Program, we designed and synthesized these plasmids and genes required for our projects allowing us to shuttle DNA easily between our in vitro and in vivo experiments. We next validated that these vectors were sufficient for cell-free expression of enzymes, performing on par with the previous state-of-the-art. Lastly, we demonstrated automated six-part DNA assemblies for $C$. autoethanogenum expression with efficiencies ranging from $68-90 \%$. We anticipate this system of plasmids will enable a framework for facile testing of biosynthetic pathways in vitro and in vivo by shortening development cycles. 


\section{Introduction}

Industrial biotechnology often seeks to produce chemical products from inexpensive and prevalent feedstocks, such as lignocellulosic biomass and syngas. ${ }^{1-3}$ While most synthetic biologists work with model organisms like Escherichia coli and Saccharomyces cerevisiae due to their ease-of-use, these organisms can be limited by accessible feedstocks, products, and stable operating environments in which to work. For example, these organisms do not naturally possess the metabolic pathways required to access the carbon in syngas; rather, researchers turn to diverse genera of non-model organisms and pathways capable of these unique biochemical transformations. ${ }^{4}$ One such genus is Clostridium, which includes the cellulolytic C. thermocellum as well as the gas-fermenting, acetogenic $C$. autoethanogenum ${ }^{5-7}$ Despite their utility for biotechnology and commercial deployment, these species grow more slowly than conventional laboratory microbes, are obligate anaerobes, and genetic tools for engineering them are still developing and far less prevalent.

Developments in cell-free synthetic biology have sought to characterize non-model organisms ${ }^{8-10}$ and rapidly test metabolic pathways in vitro. ${ }^{11-14}$ By using cell-free gene expression $(\mathrm{CFE})^{15}$ to produce enzymes directly in vitro, metabolic pathways can be tested without the need to re-engineer organisms or construct new DNA elements between each engineering cycle. ${ }^{13,16-}$ ${ }^{20}$ This approach benefits from the ability to test more enzyme variants, the ability to precisely tune reaction conditions and enzyme concentrations, and shorter engineering cycles to downselect promising candidate pathways for in vivo biochemical production. ${ }^{21}$ While cell-free pathway prototyping is carried out in a mix-and-match fashion, ${ }^{13}$ cellular expression requires assembly into operons. Additionally the specialized plasmids for Clostridium expression and those for CFE are not inherently compatible, for example require different promoters (cell-free expression typically relies the orthogonal T7 system) and additional elements such as Gram-positive replication origin, specific antibiotics cassettes and a low GC content. ${ }^{22}$ This means Clostridium optimized DNA for 
successful pathway designs identified in vitro must be separately synthesized and cloned prior to transformation in Clostridium, adding several weeks of effort and considerable costs. Streamlining this process would increase the ability to engineer non-model organisms for metabolic engineering applications.

In this work, we present a modular plasmid system on the basis of standard cell-free vector pJL1 $1^{10,19,23,24}$ and universal Clostridium shuttle vector system pMTL80000 22 to rapidly bridge cellfree prototyping efforts and strain engineering in C. autoethanogenum and reduce the overall engineering cycle time. Engineering compatible expression plasmids requires fine tuning to minimize impacts on the genetic context of open reading frames, particularly around the critically important ribosome binding site. ${ }^{13,19}$ First, we designed several plasmid architectures that resemble our top-performing cell-free expression vector, pJL1 (Addgene \#69496), and would enable flexible arrangement of genes and promoters (Golden Gate assembly ${ }^{25}$ compatibility) for expression in C. autoethanogenum. Next, we validated that these new vectors are sufficient for CFE of biosynthetic enzymes. Then, we demonstrated DNA assembly efficiency ranging from 68$90 \%$ when assembling up to six parts for $C$. autoethanogenum expression. We finally showed automation of the whole workflow on two different automation systems. This modular 'Cell-free to Clostridium' vector system along with high-throughput and automatable workflows will accelerate strain development efforts for $C$. autoethanogenum or other Clostridium species and possibly other non-model organisms, by decreasing delays in the transition between cell-free prototyping and cellular validation.

\section{Materials and Methods}

\section{Strains and Plasmids}

For generation of the 'Cell-free to Clostridium' vector system and cloning, E. coli strain TOP10 (Invitrogen) was used. First, the counter-selectable marker ccdB (flanked with Bsal recognition 
sites) was cloned into pMTL82251 and pMTL8315122 to generate the recipient Clostridium expression vectors (pCExpress). The construction of vectors pD2 and pD4 involved TOPO (Invitrogen) cloning of terminator and promoter parts (flanked with Bsal recognition sites) amplified or synthesized by $\mathrm{JGI}$ into the plasmid, pCR-blunt (Invitrogen). The 'Cell-free to Clostridium' vectors were derived from pJL1 plasmid (Addgene \#69496), modified in the T7 promoter region to contain a Bsal recognition site between the RBS and START codon in three variations to generate $\mathrm{pD} 1, \mathrm{pD} 3$, and $\mathrm{pD} 5$. All recipient and donor vectors were verified by DNA sequencing.

DNA codon-optimized genes for $C$. autoethanogenum were generated using LanzaTech's in-house codon optimization software. E. coli adapted sequences were generated using codon optimization tools from Twist Biosciences (California, USA). Genes of interest were provided by JGI in the 'Cell-free to Clostridium' vectors pD1, pD3, and pD5. All vector DNA sequences used in this study are listed in Supplementary Table 1, and all DNA parts are listed in Supplementary Table 2. The 58 modular vectors containing parts from Supplementary Table 2 are listed in Supplementary Table 3 . The biosynthetic genes used in cell-free assays are listed in Supplementary Table 4, and those used in GG assembly are listed in Supplementary Table 5.

\section{Cell-free assays}

All cell extracts for CFE were prepared with Escherichia coli BL21 Star(DE3) (NEB). ${ }^{21}$ These cells were grown, harvested, lysed, and prepared using previously described methods. ${ }^{19,26}$ CFE reactions were performed to express each enzyme individually using a modified PANOx-SP system described in previous pubications. ${ }^{27,28}$ Protein measurements were taken after $20 \mathrm{~h}$. Active super-folder GFP (sfGFP) protein yields were quantified by measuring fluorescence. Two microliters of CFE reaction was added in the middle of the flat bottom of 96-well half area black plates (Costar 3694; Corning Incorporated, Corning, NY). sfGFP was excited at $485 \mathrm{~nm}$ while 
measuring emission at $528 \mathrm{~nm}$ with a $510 \mathrm{~nm}$ cutoff filter. The fluorescence of sfGFP was converted to concentration $(\mu \mathrm{g} / \mathrm{mL})$ according to a standard curve. ${ }^{29}$ All other proteins were measured using CFE reactions with radioactive ${ }^{14} \mathrm{C}$-Leucine $(10 \mu \mathrm{M})$ supplemented for incorporation during protein production. We used trichloroacetic acid (TCA) to precipitate radioactive protein samples. Radioactive counts from TCA-precipitated samples was measured by liquid scintillation to then quantify soluble and total yields of each protein produced as previously reported (MicroBeta2; PerkinEImer). ${ }^{27,30}$

\section{Golden Gate assembly using manual workflow}

Two- to six-part DNA assemblies were performed using GeneArt Type Ils (Bsal) assembly kit (Invitrogen, CA). Specifically, 75 ng of recipient vector was used. Other parts (pD1, pD2, pD3, $\mathrm{pD} 4$, and $\mathrm{pD} 5$ ) were added in 1:1 molar ratio with respect to the recipient vector along with the GeneArt Type Ils enzyme mix. The reaction was then incubated in a thermocycler $\left(37^{\circ} \mathrm{C}\right.$ for 1 $\min , 16{ }^{\circ} \mathrm{C}$ for $1 \mathrm{~min}$, cycled $30 \mathrm{X}$, followed by cooling at $4{ }^{\circ} \mathrm{C}$ ). Afterwards, the assembly mixture was transformed into E. coli Top 10 chemically competent cells (ThermoFisher Scientific, CA), and plated onto LB agar containing appropriate antibiotics. Resulting colonies were screened via PCR for presence of the parts cloned, followed by sequence confirmation via NGS.

\section{Golden Gate assembly using automated workflow}

Two automated assembly workflows were developed, either using the liquid handling robot Hamilton STARLet or the Labcyte Echo $525 .{ }^{31}$ The assembly reactions were carried out with the final concentration for each individual DNA part was $2 \mathrm{nM}^{25}$ The assembly reaction volume for Hamilton STARLet was $20 \mu \mathrm{L}$ prepared as follows: $2 \mu \mathrm{L}$ of each DNA part (10 nM), $10 \mu \mathrm{L}$ GeneArt Type Ils Assembly Kit Bsal (Invitrogen A15917), and deionized water to a total of $20 \mu \mathrm{L}$. When using the Labcyte Echo 525, the reaction volume was downsized to a final volume 
of $2 \mu \mathrm{L}$. All DNA samples were quantified by absorbance at $280 \mathrm{~nm}$, employing a NanoDrop 2000 spectrophotometer (Thermo Fisher Scientific). Reactions were incubated in an INHECO heat block using the following parameters: $37^{\circ} \mathrm{C}$ for $2 \mathrm{~h}, 50^{\circ} \mathrm{C}$ for $5 \mathrm{~min}, 80^{\circ} \mathrm{C}$ for $10 \mathrm{~min}$, then stored at $-20^{\circ} \mathrm{C}$ until transformation. Transformations were also performed using the INHECO blocks: $2 \mu \mathrm{L}$ of each reaction mix was added to $20 \mu \mathrm{L}$ of Invitrogen One Shot Top10 chemically competent cells (C404003) and incubated for 20 min at $4{ }^{\circ} \mathrm{C}$. Cells were then heat-shocked at 60 ${ }^{\circ} \mathrm{C}$ for $45 \mathrm{sec}$, then recovered for $2 \mathrm{~min}$ at $4{ }^{\circ} \mathrm{C}$. Afterwards, $180 \mu \mathrm{L}$ of Super Optimal Broth (Invitrogen 15544034) with catabolite repression (SOC) media was added to cell mixtures, and cells were recovered at $37^{\circ} \mathrm{C}$ for $2 \mathrm{~h}$. Finally, $7 \mu \mathrm{L}$ of each transformation reaction consisting of undiluted culture volume was plated on Lennox Lysogeny Broth (LB) + agar plates containing the appropriate antibiotic and incubated overnight at $37^{\circ} \mathrm{C}$. We randomly chose two colonies to sequence throughout the assembled regions. NGS sequencing confirmed that more than $90 \%$ of the clones screened showed complete assemblies.

\section{Results and Discussion}

\section{Design of a modular 'cell-free to Clostridium' vector system}

Our goal was to develop a DNA vector system that would enable easy exchange of DNA between cell-free plasmids and cellular plasmids. This cell-free to Clostridium framework would minimize repetitive DNA synthesis and subcloning, allowing for facile and rapid testing of biosynthetic pathways in vitro and in vivo (Figure 1A). To achieve this goal, CFE expression plasmids were modified via addition of Golden Gate (GG) sites so that these can be used directly for multiple DNA parts assembly directly into Clostridium expression vectors (Figure 1B). With such a system in place, genes could be ordered once with Clostridium codon-adapted sequences in these plasmids, prototyped in cell-free reactions using these plasmids, and then the best 
performing gene variants could be assembled from the same plasmids into in vivo expression plasmids via one-step GG assembly.

As a starting point, we designed six total vectors. Three vectors, $\mathrm{pD} 1, \mathrm{pD} 3$, and $\mathrm{pD} 5$, were constructed by adding GG sites (Bsal recognition sites) within the T7 promoter region of the pJL1 vector (Addgene \#69496), a standard CFE expression plasmid. These vectors were designed to serve as gene donor vectors for assembly in a new recipient vector based on pMTL80000 universal Clostridium expression vectors ${ }^{22}$ with the addition of two GG sites flanking a $c c d B$ survival gene along with Clostridium promoter and terminator flanking the GG sites. We also constructed pD2 and pD4 to serve as promoter-terminator donor vectors. This system of six vectors (5 donor vectors and 1 recipient vector) would allow for in vitro expression of genes using $\mathrm{pD} 1, \mathrm{pD} 3$, and $\mathrm{pD} 5$, followed by one-step assembly of up to six DNA parts (inserts supplied by pD1, pD2, pD3, pD4, and pD5) directly into our Clostridium expression vector. We note that different combinations of these vectors can be used to assemble one-gene insertions (Supplementary Figure 1A) or two-gene insertions (Supplementary Figure 1B) when fewer genes are desired. It is also possible to combine more than three genes in an expression operon by using multi-cistronic donor vectors (Supplementary Figure 1C).

Utilizing JGI's gene synthesis program, the GG system was expanded to create recipient and donor vectors with varying promoters, such as $\mathrm{P}_{f d x}{ }^{17}, \mathrm{P}_{p t a}{ }^{18}, \mathrm{P}_{p f o r}{ }^{19}$, and $\mathrm{P}_{w l}{ }^{18}$. Additionally, $\mathrm{GG}$ sites were varied in recipient vectors to allow assembly of anywhere between two to six parts with varying promoters, resulting in a total of 58 modular vectors (Supplementary Figure 1D; Supplementary Table 3). The variety of assembly options using different DNA parts (Supplementary Table 2) increases the versatility of this vector system. 
a

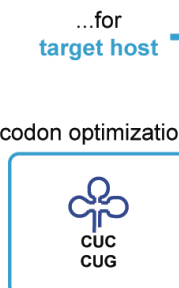

of genes

for

E. coli

$\longrightarrow$...into traditional

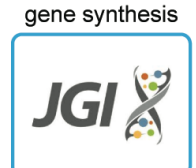

\& cloning cell-free vectors

b

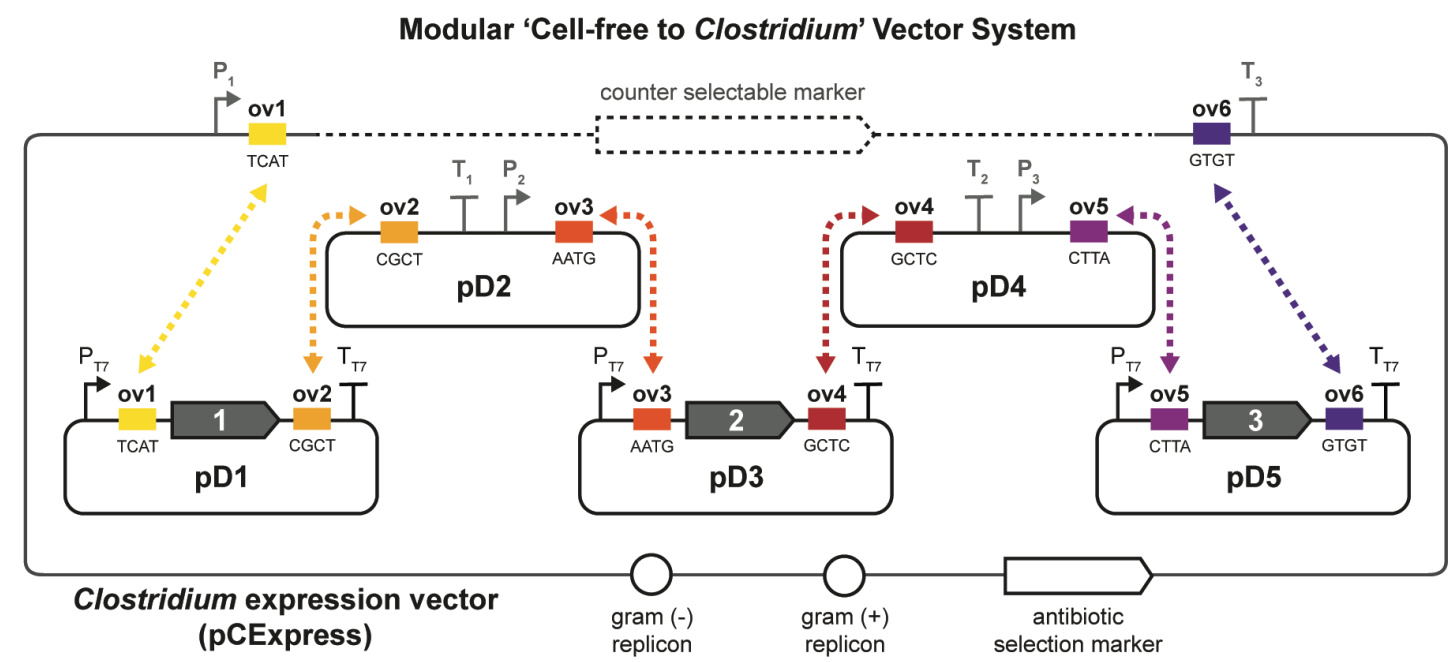

New Workflow

2x faster

$20 \%$ cheaper

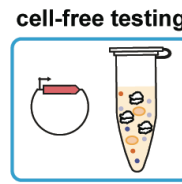

\& down-selection of candidate genes

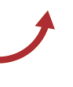

$\checkmark$ I coptimization , of genes for

pathway assembly of operons with down-selected genes directly from modular cell-free vectors

Old Workflow $\$ 100-300$ more per gene

- - - - - -

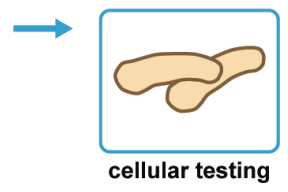

gene synthesis $\&$ cloning into
donor vectors

$\longrightarrow \quad \begin{aligned} & \text { pathway assembly } \\ & \text { of operons with }\end{aligned}$ of operons with
down-selected genes down-selected genes

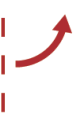

1 additional month 
CTTA were introduced between the ribosome binding site (RBS) and start codon, which increased the spacer length between these two elements by 1 to 3 nucleotides. This created three distinct donor vectors each with three possible Bsal cut sites. We evaluated each of these nine designs in a cell-free gene expression reaction based on the PANOx-SP system to produce sfGFP to first assess the impact of GG sites on protein expression. After $20 \mathrm{~h}$, cell-free reactions produced comparable or slightly greater concentrations of sfGFP than the unaltered pJL1 plasmid (Figure 2B). For the donor vectors to be compatible we had to choose the same variant for each of the three vectors. Thus, we chose variant 2 as the highest-performing set. Variant 2 GG vectors were validated further with expression of the enzymes phosphotransbutyrylase (Ptb) and butyrate kinase (Buk) from butyric acid metabolism in C. acetobutylicum ATCC 824 (Figure 2C). This experiment highlights the importance of genetic context for expression of different proteins, yielding variable amount of protein for Ptb and Buk despite nearly identical expression of sfGFP.

We next evaluated whether $C$. autoethanogenum-optimized genes would be sufficiently expressed in our established cell-free assays. To test this, we constructed a panel of 15 Clostridium-optimized biosynthesis genes (Supplementary Table 4) related to acid/alcohol fermentation from a variety of organisms in pD1, pD3, and pD5. After a 20-h CFE reaction we observed a range of expression all significantly lower (10-fold) than what we saw for E. coli-codonoptimized sfGFP, Ptb, or Buk (Figure 2D). For enzymes that are not expressed well, separately expressing the E. coli-codon-optimized versions can improve enzyme expression (Supplementary Figure 2; Supplementary Table 4). Although the soluble protein yields are generally lower using C. autoethanogenum (31\% GC content) codon-optimized sequences in $E$. coli-based (50\% GC content) cell extract, these concentrations should still be sufficient for in vitro pathway prototyping. Expressing enzymes at concentrations greater than $1 \mu \mathrm{M}$ provides at least $0.1 \mu \mathrm{M}$ enzyme after dilution upon pathway assembly in vitro which we have found to be sufficient for prototyping. ${ }^{13}$ When necessary, E. coli-codon optimization can be used. With GG-compatible vectors at hand we next sought construct in vivo expression plasmids. 

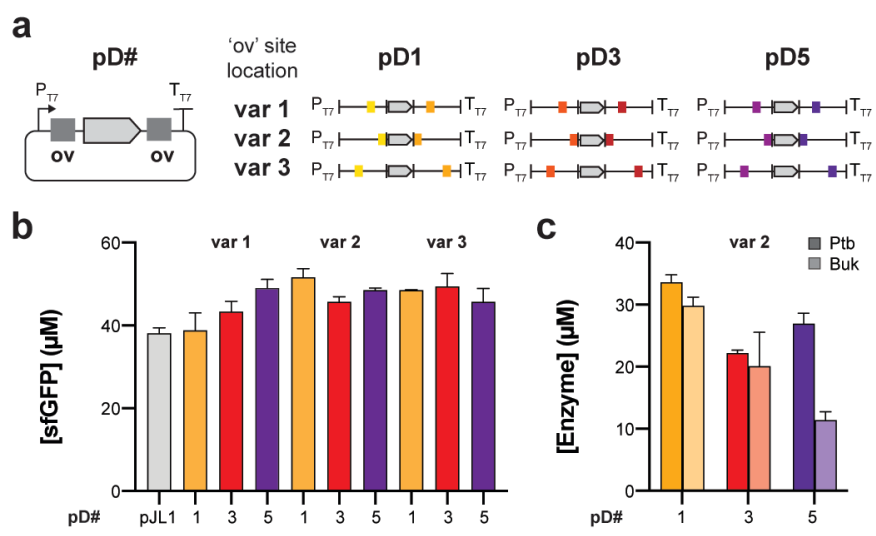

d

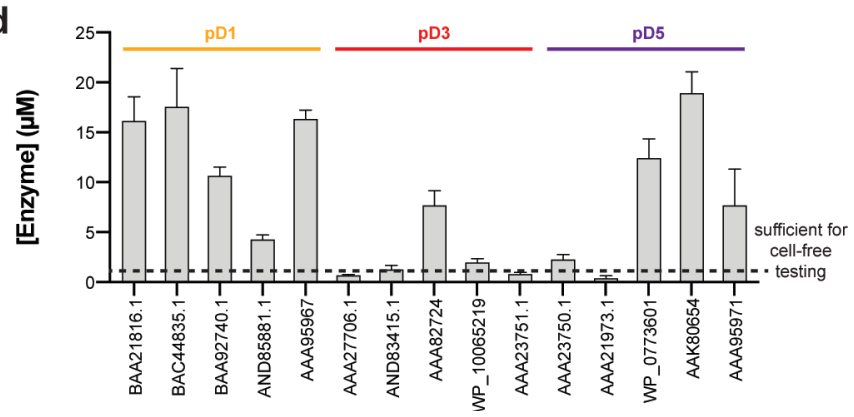

Figure 2. Cell-free expression of Golden Gate compatible vectors is sufficient for prototyping biosynthetic enzymes. (a) We tested three variants (change in where Bsal sites are located) of each of the three donor plasmids in CFE using a reporter sfGFP. (b) We measure sfGFP concentration by fluorescence at $20 \mathrm{~h}$ after reaction start. Data is shown for $\mathrm{n}=2$ independent experiments with average error. (c) We switched the sfGFP reporter for Ptb and Buk in variant 2 for each of the three donor vectors and measured protein concentration at $20 \mathrm{~h}$ via radioactive leucine incorporation. Data is shown for $n=2$ independent experiments with average error. (d) 15 enzymes of interest for acid and alcohol fermentation were codon optimized for $C$. autoethanogenum and cloned into pD1, pD2, and pD3. Protein expression was measured at 20 $\mathrm{h}$ for $\mathrm{n}=3$ independent experiments. All error bars represent 1 s.d.

\section{Six-part DNA assembly from CFE vectors into Clostridium expression plasmid}

Once the $\mathrm{pD}$ vectors were successfully validated in CFE, these modified vectors were then used for testing the efficiency of multiple-part assembly directly into a Clostridium expression vector with a variety of biosynthetic genes. Specifically, we carried out a six-part GG assembly that contained: (i) a recipient vector based on pMTL8315 backbone containing a promoter (P1) and terminator (T3) flanking the two GG sites (pCExpress), (ii) pD2 and pD4, both containing terminator and promoter combinations (i.e., T1-P2 and T2-P3), and (iii) pD1, pD3, and pD5 containing gene 1, gene 2, and gene 3 (Figure 3A; Supplementary Table 1). The assembly mixture was transformed into our E. coli cloning strain and six colonies were picked and 
genotyped by PCR which indicated $90-100 \%$ of the picked colonies had plasmids with all six parts correctly assembled (Figure 3B). These were confirmed via sequencing. The six-part assembly was validated using a different set of genes and promoter-terminator combinations for at least five additional designs (Supplementary Table 5). In a total of 20 manual assemblies were carried out with efficiency ranging from $70-95 \%$.

\section{Workflow automation}

Workflow automation can improve throughput and reliability. CFE reactions can routinely be performed using liquid-handling robotics. ${ }^{35,36}$ These reactions can be scaled down to $2 \mu \mathrm{L}$ without significant changes in protein expression. ${ }^{37}$ In addition, GG assembly for in vivo expression can also be automated. After demonstrating successful assembly of up to six DNA parts using a manual workflow, we then developed an automated workflow to increase our DNA assembly throughput (Figure 3A). Due to the complexity of biological systems, it is often necessary to test a large number of enzyme homologs along with different promoters to obtain an optimal engineering solution. Indeed, testing just five homologs and three promoters for a three gene operon would yield 3,375 different permutations. However, this experimental throughput is difficult and laborious when using manual techniques and procedures. Automated, well-informed designs help to increase the number of designs that can be generated, the speed these designs can be generated, and it helps to narrow down the design space prioritizing the best candidates to be built and tested, saving lab resources. ${ }^{38}$ In order to increase throughput, efficiency, and accuracy of our strain engineering pipeline, free up researchers from repetitive tasks, and increase results reproducibility, we validated a Golden Gate DNA assembly automated protocol on two automation systems. Both the design of constructs and the worklists to run the experiments were generated by $\mathrm{J} 5$ software ${ }^{39,40}$ We assembled three- to six-part GG assemblies using both a Hamilton STARLet liquid-handling robot and a Labcyte Echo 525 acoustic liquid-handling robot with greater than $90 \%$ efficiencies. 


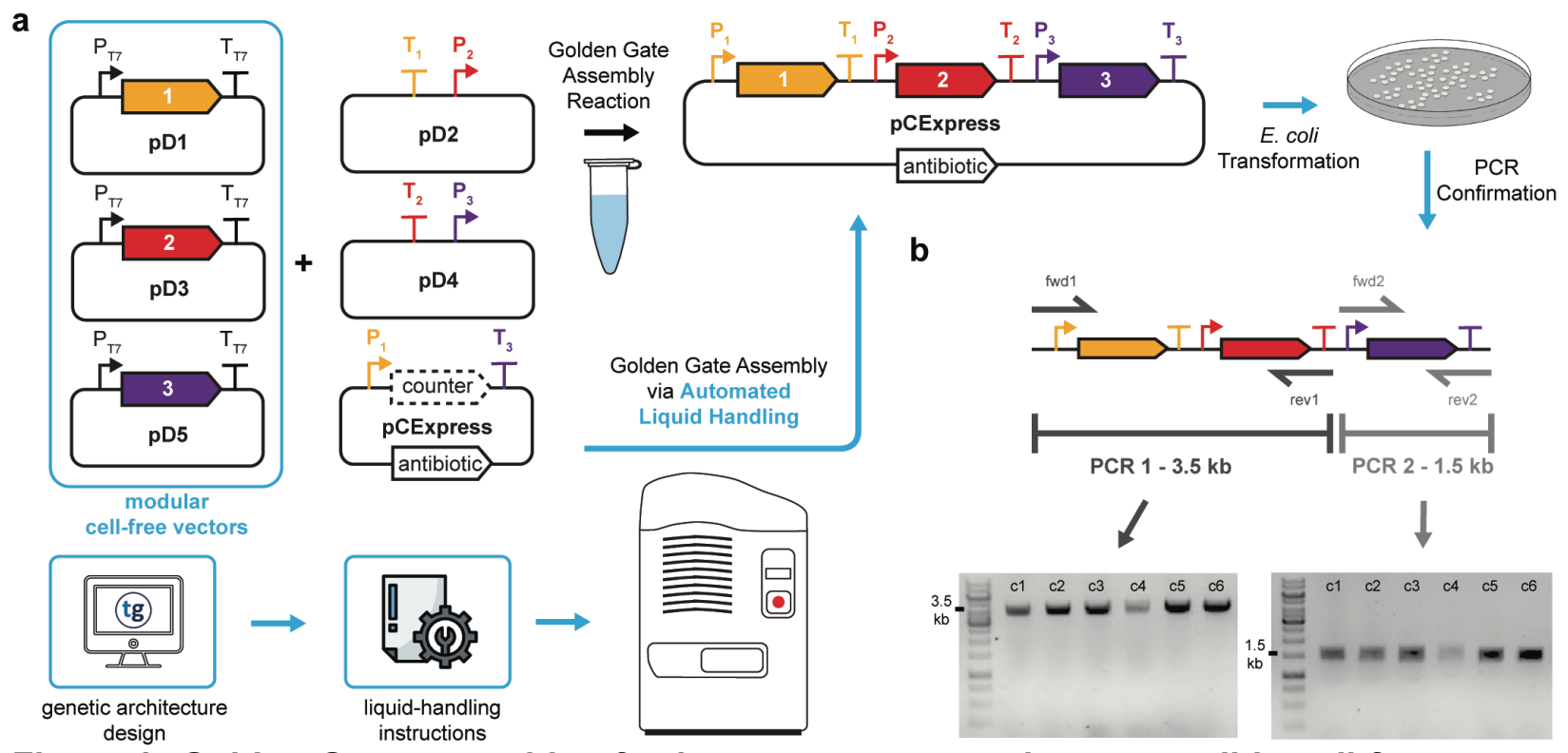

Figure 3. Golden Gate assembly of a 3-gene construct using compatible cell-free vector system. (a) A schematic representation of our Golden Gate assembly workflow including automated assembly consisting of computational design of plasmids, liquid-handling instructions, plasmid assembly, and plasmid confirmation. (b) PCR confirmation of plasmid assembly in six colonies containing the constructed Clostridium expression vector.

\section{Conclusion}

In this study, we describe a set of modular vectors for both cell-free gene expression and cloning into Clostridium expression plasmids. This framework allows facile testing of biosynthetic pathways in vitro and in vivo for shorter engineering cycles and enables an improved workflow between our in vitro team, our in vivo team, and JGI, without lengthy and costly re-synthesis and/or subcloning. The 'Cell-free to Clostridium' vector system is easy to use for Golden Gate assembly of up to six parts (three open reading frames with unique promoter and terminator sequences) at once with up to $90 \%$ efficiencies and feeds directly into the JGI's Community Science Program platform. For longer operons, genes can be sequentially located on each of the CFE vectors (pD1, pD3, and pD5). These vectors along with laboratory automation have already increased the speed and efficiency of our workflows and will continue to facilitate the ability to prototype biosynthetic pathways in vitro followed by in vivo cloning pipelines. Standardization of these vector systems allows for new simplified workflows. The pJL1 cell-free vector and variants 
thereof are routinely used in multiple bacterial cell-free systems (i.e., E. coli, ${ }^{19}$ Clostridium, $^{10}$ Pseudomonas, ${ }^{23}$ Streptomyces, ${ }^{24,41}$ Vibrio natriegens $\left.{ }^{42,43}\right)$. In addition, the pMTL vector system has been demonstrated in several Clostridia species (i.e., autoethanogenum, ljungdahlii, acetobutylicum, beijerinckii, difficile, sporogeneses, perfringens, pasteurianum, tyrobutyricum) as

well as other Gram-negative and Gram-positive model organisms such as E. coli and Bacillus. ${ }^{22,44}$ Taken together, the breadth of bacterial cell-free systems that can use the pJL1 vector and ubiquity of Golden Gate cloning suggests broad applicability of our plasmid vector system. Looking forward, we anticipate this system of vectors will allow researchers to integrate more in vitro prototyping practices into their existing workflows across multiple organisms to speed up metabolic engineering efforts.

\section{Acknowledgements}

We would like to acknowledge Jan-Fang Chen, Robert Evans, Yasuo Yoshikuni, and Miranda Harmon-Smith from the U.S. Department of Energy Joint Genome Institute, a DOE Office of Science User Facility, for their DNA synthesis, DNA assembly, and support in this work as part of the Community Science Program (CSP).

Funding: This work was supported by the U.S. Department of Energy (DOE) Biological and Environmental Research Division (BER), Genomic Science Program (GSP) for funding of this project under Contract No. DE-SC0018249. We also thank the Joint Genome Institute Community Science Program Project 503280. The work conducted by the U.S. Department of Energy Joint Genome Institute, a DOE Office of Science User Facility, is supported by the Office of Science of the U.S. Department of Energy under Contract No. DE-AC02-05CH11231. We also thank the following investors in LanzaTech's technology: BASF, CICC Growth Capital Fund I, CITIC Capital, Indian Oil Company, K1W1, Khosla Ventures, the Malaysian Life Sciences, Capital Fund, L. P., 
Mitsui, the New Zealand Superannuation Fund, Novo Holdings A/S, Petronas Technology Ventures, Primetals, Qiming Venture Partners, Softbank China, and Suncor.

\section{Conflicts of Interest}

A provisional patent has been filed on this vector system (US 62/943,036).

\section{Author Contributions}

A.S.K., F.E.L., A.J., M.K., and M.C.J. conceived the study. A.S.K., B.V., and B.J.R. performed cell-free experiments. F.E.L., S.G., A.G., and M.P. performed in vivo experiments. S.D.S., M.K., and M.C.J. provided supervision. All authors wrote the manuscript.

\section{References}

1 Clomburg, J. M., Crumbley, A. M. \& Gonzalez, R. Industrial biomanufacturing: The future of chemical production. Science 355, doi:10.1126/science.aag0804 (2017).

2 Liu, Z., Wang, K., Chen, Y., Tan, T. \& Nielsen, J. Third-generation biorefineries as the means to produce fuels and chemicals from CO2. Nature Catalysis 3, 274-288, doi:10.1038/s41929-019-0421-5 (2020).

3 Köpke, M. \& Simpson, S. D. Pollution to products: recycling of 'above ground' carbon by gas fermentation. Curr Opin Biotechnol 65, 180-189, doi:10.1016/j.copbio.2020.02.017 (2020).

4 Yan, Q. \& Fong, S. S. Challenges and Advances for Genetic Engineering of Non-model Bacteria and Uses in Consolidated Bioprocessing. Front Microbiol 8, 2060, doi:10.3389/fmicb.2017.02060 (2017).

5 Tracy, B. P., Jones, S. W., Fast, A. G., Indurthi, D. C. \& Papoutsakis, E. T. Clostridia: the importance of their exceptional substrate and metabolite diversity for biofuel and biorefinery applications. Curr Opin Biotechnol 23, 364-381, doi:10.1016/j.copbio.2011.10.008 (2012).

6 Lynd, L. R. et al. in Industrial Biotechnology: Microorganisms Vol. 1 (eds C. Wittmann \& J. C. Liao) (Wiley-VCH Verlag GmbH \& Co. KGaA, 2016).

7 Marcellin, E. et al. Low carbon fuels and commodity chemicals from waste gases systematic approach to understand energy metabolism in a model acetogen. Green Chemistry 18, 3020-3028, doi:10.1039/c5gc02708j (2016).

8 Yim, S. S. et al. Multiplex transcriptional characterizations across diverse bacterial species using cell-free systems. Mol Syst Biol 15, e8875, doi:10.15252/msb.20198875 (2019). 
9 Moore, S. J. et al. Rapid acquisition and model-based analysis of cell-free transcriptiontranslation reactions from nonmodel bacteria. Proc Natl Acad Sci U S A 115, E4340E4349, doi:10.1073/pnas.1715806115 (2018).

10 Krüger, A. et al. Development of a clostridia-based cell-free system for prototyping genetic parts and metabolic pathways. BioRxiv, doi:10.1101/2020.03.11.987826 (2020).

11 Moore, S. J., MacDonald, J. T. \& Freemont, P. S. Cell-free synthetic biology for in vitro prototype engineering. Biochem Soc Trans 45, 785-791, doi:10.1042/BST20170011 (2017).

12 Jiang, L., Zhao, J., Lian, J. \& Xu, Z. Cell-free protein synthesis enabled rapid prototyping for metabolic engineering and synthetic biology. Synth Syst Biotechnol 3, 90-96, doi:10.1016/j.synbio.2018.02.003 (2018).

13 Karim, A. S. et al. In vitro prototyping and rapid optimization of biosynthetic enzymes for cellular design. BioRxiv, doi:10.1101/685768 (2019).

14 Liu, Z. et al. In Vitro Reconstitution and Optimization of the Entire Pathway to Convert Glucose into Fatty Acid. ACS Synth Biol 6, 701-709, doi:10.1021/acssynbio.6b00348 (2017).

15 Silverman, A. D., Karim, A. S. \& Jewett, M. C. Cell-free gene expression: an expanded repertoire of applications. Nat Rev Genet 21, 151-170, doi:10.1038/s41576-019-0186-3 (2020).

16 Grubbe, W. S., Rasor, B. J., Krüger, A., Jewett, M. C. \& Karim, A. S. Cell-free styrene biosynthesis at high titers. bioRxiv, 2020.2003.2005.979302, doi:10.1101/2020.03.05.979302 (2020).

17 Dudley, Q. M., Karim, A. S., Nash, C. J. \& Jewett, M. C. Cell-free prototyping of limonene biosynthesis using cell-free protein synthesis. BioRxiv, 2020.2004.2023.057737, doi:10.1101/2020.04.23.057737 (2020).

18 Kightlinger, W. et al. A cell-free biosynthesis platform for modular construction of protein glycosylation pathways. Nat Commun 10, 5404, doi:10.1038/s41467-019-12024-9 (2019).

19 Karim, A. S. \& Jewett, M. C. A cell-free framework for rapid biosynthetic pathway prototyping and enzyme discovery. Metab Eng 36, 116-126, doi:10.1016/j.ymben.2016.03.002 (2016).

20 Dudley, Q. M., Nash, C. J. \& Jewett, M. C. Cell-free biosynthesis of limonene using enzyme-enriched Escherichia coli lysates. Synth Biol (Oxf) 4, ysz003, doi:10.1093/synbio/ysz003 (2019).

21 Karim, A. S. \& Jewett, M. C. Cell-Free Synthetic Biology for Pathway Prototyping. Methods Enzymol 608, 31-57, doi:10.1016/bs.mie.2018.04.029 (2018).

22 Heap, J. T., Pennington, O. J., Cartman, S. T. \& Minton, N. P. A modular system for Clostridium shuttle plasmids. J Microbiol Methods 78, 79-85, doi:10.1016/j.mimet.2009.05.004 (2009).

23 Wang, H., Li, J. \& Jewett, M. C. Development of a Pseudomonas putida cell-free protein synthesis platform for rapid screening of gene regulatory elements. Synthetic Biology 3 , doi:10.1093/synbio/ysy003 (2018).

$24 \mathrm{Li}$, J., Wang, H., Kwon, Y. C. \& Jewett, M. C. Establishing a high yielding streptomycesbased cell-free protein synthesis system. Biotechnol Bioeng 114, 1343-1353, doi:10.1002/bit.26253 (2017).

25 Engler, C., Kandzia, R. \& Marillonnet, S. A one pot, one step, precision cloning method with high throughput capability. PLoS One 3, e3647, doi:10.1371/journal.pone.0003647 (2008).

26 Kwon, Y. C. \& Jewett, M. C. High-throughput preparation methods of crude extract for robust cell-free protein synthesis. Sci Rep 5, 8663, doi:10.1038/srep08663 (2015). 
27 Jewett, M. C. \& Swartz, J. R. Mimicking the Escherichia coli cytoplasmic environment activates long-lived and efficient cell-free protein synthesis. Biotechnology and bioengineering 86, 19-26, doi:10.1002/bit.20026 (2004).

28 Jewett, M. C. \& Swartz, J. R. Substrate replenishment extends protein synthesis with an in vitro translation system designed to mimic the cytoplasm. Biotechnol Bioeng 87, 465472, doi:10.1002/bit.20139 (2004).

29 Hong, S. H. et al. Cell-free protein synthesis from a release factor 1 deficient Escherichia coli activates efficient and multiple site-specific nonstandard amino acid incorporation. ACS Synth Biol 3, 398-409, doi:10.1021/sb400140t (2014).

30 Jewett, M. C., Calhoun, K. A., Voloshin, A., Wuu, J. J. \& Swartz, J. R. An integrated cellfree metabolic platform for protein production and synthetic biology. Mol Syst Biol 4, 220, doi:10.1038/msb.2008.57 (2008).

31 Walsh, D. I., 3rd et al. Standardizing Automated DNA Assembly: Best Practices, Metrics, and Protocols Using Robots. SLAS Technol 24, 282-290, doi:10.1177/2472630318825335 (2019).

32 Shin, J. \& Noireaux, V. Efficient cell-free expression with the endogenous E. Coli RNA polymerase and sigma factor 70. J Biol Eng 4, 8, doi:10.1186/1754-1611-4-8 (2010).

33 Yeung, E. et al. Biophysical Constraints Arising from Compositional Context in Synthetic Gene Networks. Cell Syst 5, 11-24 e12, doi:10.1016/j.cels.2017.06.001 (2017).

34 Des Soye, B. J., Gerbasi, V. R., Thomas, P. M., Kelleher, N. L. \& Jewett, M. C. A Highly Productive, One-Pot Cell-Free Protein Synthesis Platform Based on Genomically Recoded Escherichia coli. Cell Chem Biol 26, 1743-1754 e1749, doi:10.1016/j.chembiol.2019.10.008 (2019).

35 Caschera, F. et al. High-Throughput Optimization Cycle of a Cell-Free Ribosome Assembly and Protein Synthesis System. ACS Synth Biol 7, 2841-2853, doi:10.1021/acssynbio.8b00276 (2018).

36 Karim, A. S., Heggestad, J. T., Crowe, S. A. \& Jewett, M. C. Controlling cell-free metabolism through physiochemical perturbations. Metab Eng 45, 86-94, doi:10.1016/j.ymben.2017.11.005 (2018).

37 Marshall, R., Garamella, J., Noireaux, V. \& Pierson, A. High-throughput Microliter-Sized Cell-Free Transcription-Translation Reactions for Synthetic Biology Applications Using the Echo® 550 Liquid Handler. Labcyte Application Note, App-G124 (2018).

38 Densmore, D. M. \& Bhatia, S. Bio-design automation: software + biology + robots. Trends Biotechnol 32, 111-113, doi:10.1016/j.tibtech.2013.10.005 (2014).

39 Hillson, N. J., Rosengarten, R. D. \& Keasling, J. D. j5 DNA assembly design automation software. ACS Synth Biol 1, 14-21, doi:10.1021/sb2000116 (2012).

40 Hillson, N. J. j5 DNA assembly design automation. Methods Mol Biol 1116, 245-269, doi:10.1007/978-1-62703-764-8_17 (2014).

$41 \mathrm{Xu}$, H., Liu, W. Q. \& Li, J. Translation Related Factors Improve the Productivity of Streptomyces-Based Cell-Free Protein Synthesis System. ACS Synth Biol, doi:10.1021/acssynbio.0c00140 (2020).

42 Des Soye, B. J., Davidson, S. R., Weinstock, M. T., Gibson, D. G. \& Jewett, M. C. Establishing a High-Yielding Cell-Free Protein Synthesis Platform Derived from Vibrio natriegens. ACS Synth Biol 7, 2245-2255, doi:10.1021/acssynbio.8b00252 (2018).

43 Wiegand, D. J., Lee, H. H., Ostrov, N. \& Church, G. M. Establishing a Cell-Free Vibrio natriegens Expression System. ACS Synth Biol 7, 2475-2479, doi:10.1021/acssynbio.8b00222 (2018).

44 Minton, N. P. et al. A roadmap for gene system development in Clostridium. Anaerobe 41, 104-112, doi:10.1016/j.anaerobe.2016.05.011 (2016). 


\section{Supplementary Information for}

\section{Modular cell-free expression plasmids to accelerate biological design in cells}

Ashty S. Karim ${ }^{1,2,3, \#}$, Fungmin (Eric) Liew ${ }^{4, \#}$, Shivani Garg ${ }^{4}$, Bastian Vögeli ${ }^{1,2,3}$, Blake J.

Rasor $^{1,2,3}$, Aislinn Gonnot ${ }^{4}$, Marilene Pavan ${ }^{4}$, Alex Juminaga ${ }^{4}$, Séan D. Simpson ${ }^{4}$, Michael

Köpke $^{4, *}$, Michael C. Jewett ${ }^{1,2,3,5, *}$

${ }^{1}$ Department of Chemical and Biological Engineering, Northwestern University, Evanston, IL 60208, USA

${ }^{2}$ Chemistry of Life Processes Institute, Northwestern University, Evanston, IL 60208, USA

${ }^{3}$ Center for Synthetic Biology, Northwestern University, Evanston, IL 60208, USA

${ }^{4}$ LanzaTech Inc., 8045 Lamon Ave Suite 400, Skokie, IL 60077, USA

${ }^{5}$ Simpson Querrey Institute, Northwestern University, Chicago, IL 60611, USA

\#These authors contributed equally to this work

${ }^{*}$ Corresponding Authors: Michael C. Jewett, m-jewett@northwestern.edu and Michael Köpke, Michael.Koepke@lanzatech.com

\section{Contents}

Tables 1-5

Figures 1-2 
Supplementary Table 1. DNA Vector Sequences. Below is a table of all vectors used in this study. The vector type is what is referenced throughout the manuscript.

\begin{tabular}{|c|c|c|}
\hline $\begin{array}{c}\text { Vector } \\
\text { Type }\end{array}$ & $\begin{array}{l}\text { Vector } \\
\text { Name }\end{array}$ & Vector DNA Sequence \\
\hline pCExpress & $\begin{array}{l}\text { pMTL8315 } \\
\text { 16_Pfer_Tp } \\
\text { epN }\end{array}$ & 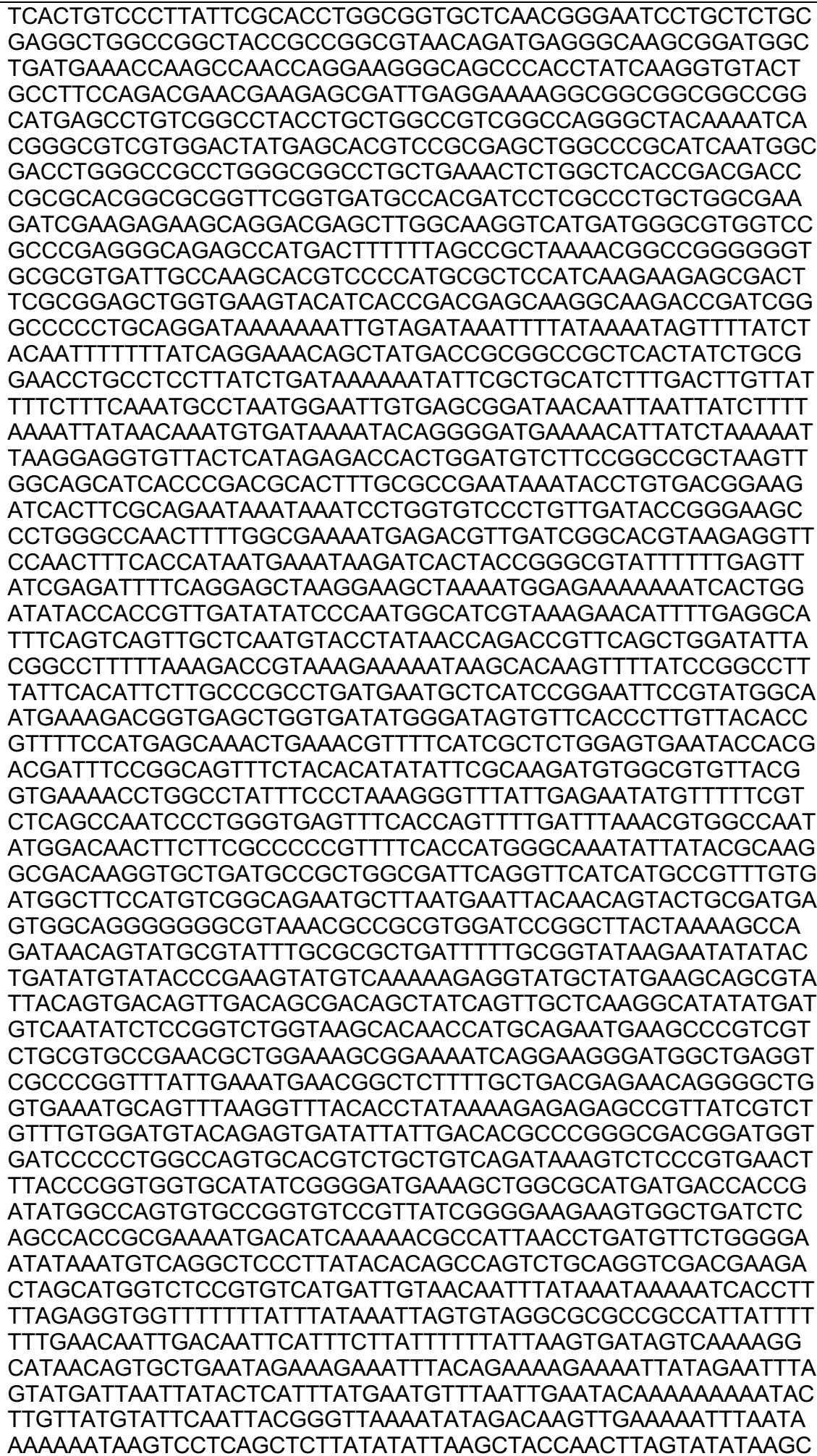 \\
\hline
\end{tabular}




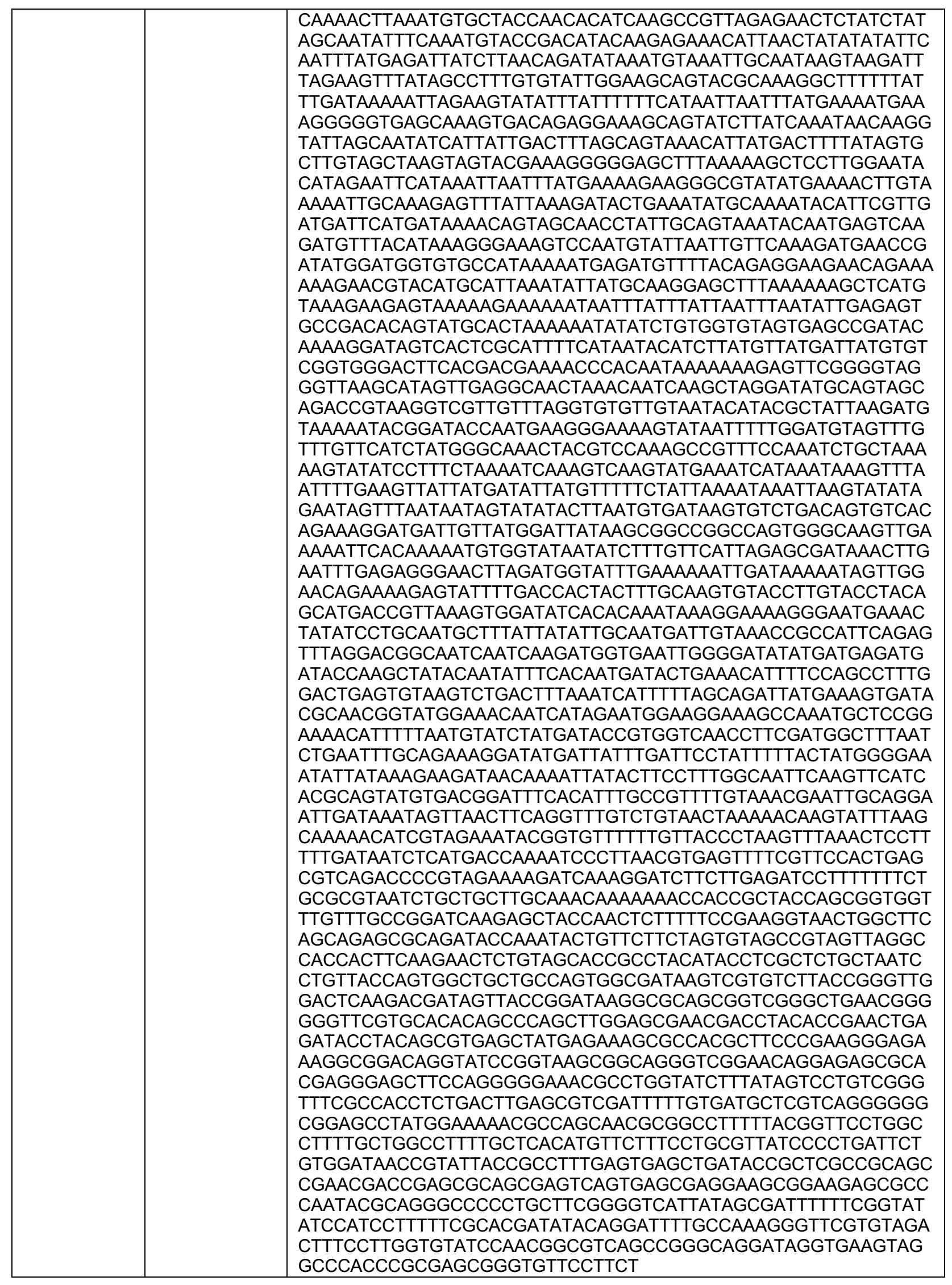




\begin{tabular}{|c|c|c|}
\hline pD1 & $\begin{array}{l}\text { P8_pJLD1_ } \\
\text { Gene1 }\end{array}$ & 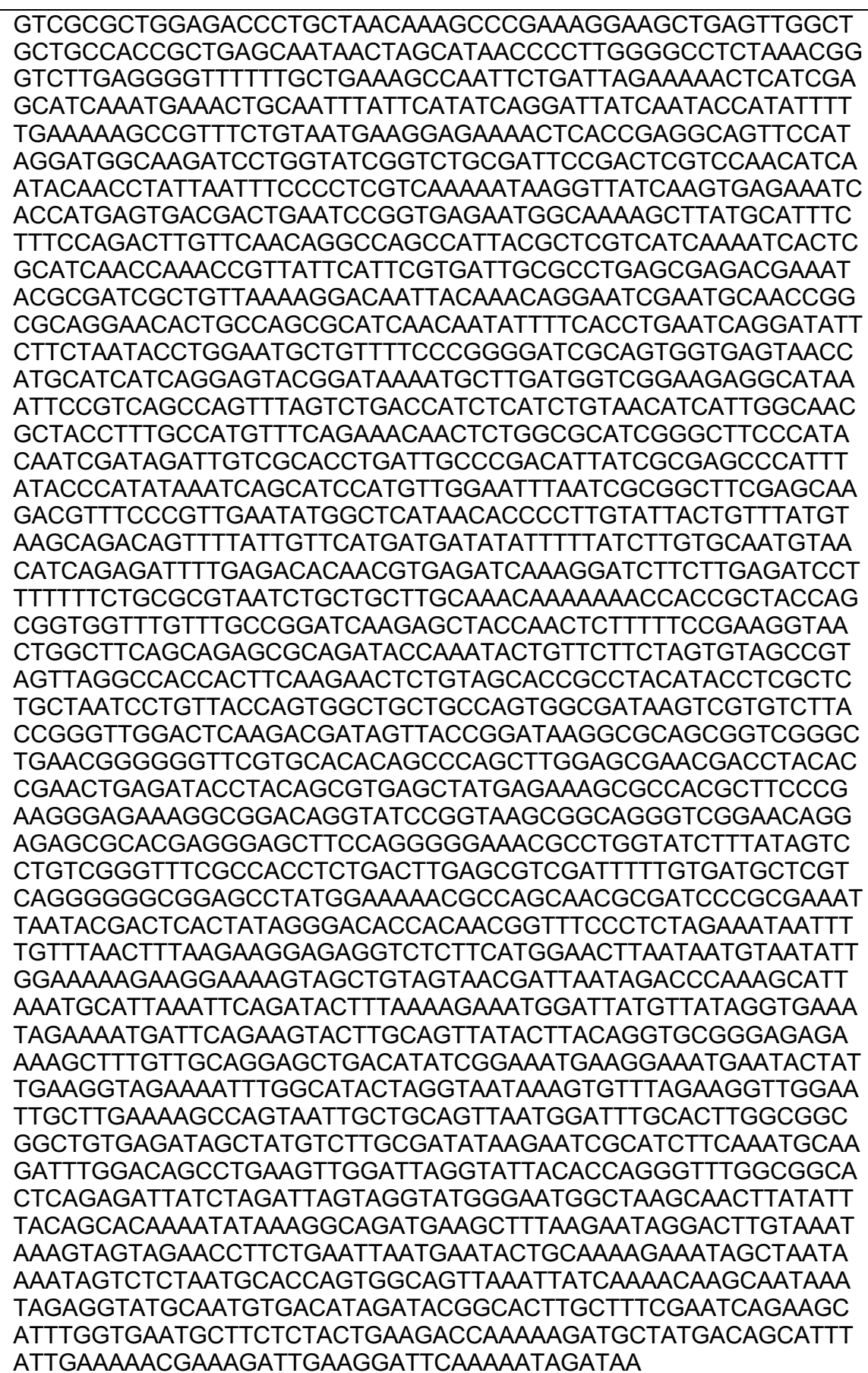 \\
\hline
\end{tabular}




\begin{tabular}{|c|c|c|}
\hline pD2 & $\begin{array}{l}\text { pDN2_GG2 } \\
\text { _Pfer_GG3 }\end{array}$ & 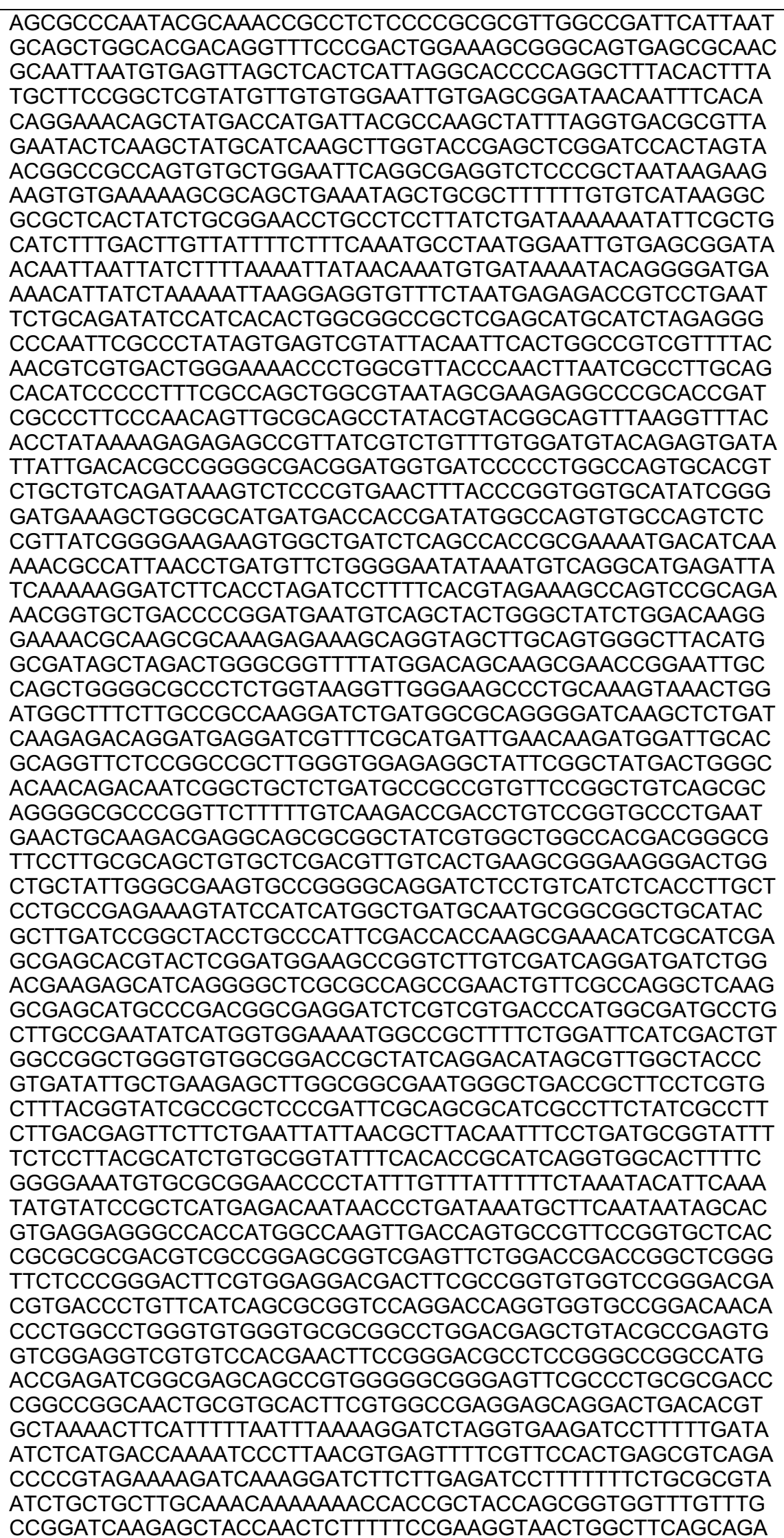 \\
\hline
\end{tabular}


bioRxiv preprint doi: https://doi.org/10.1101/2020.07.22.216267; this version posted July 22, 2020. The copyright holder for this preprint (which was not certified by peer review) is the author/funder. All rights reserved. No reuse allowed without permission.

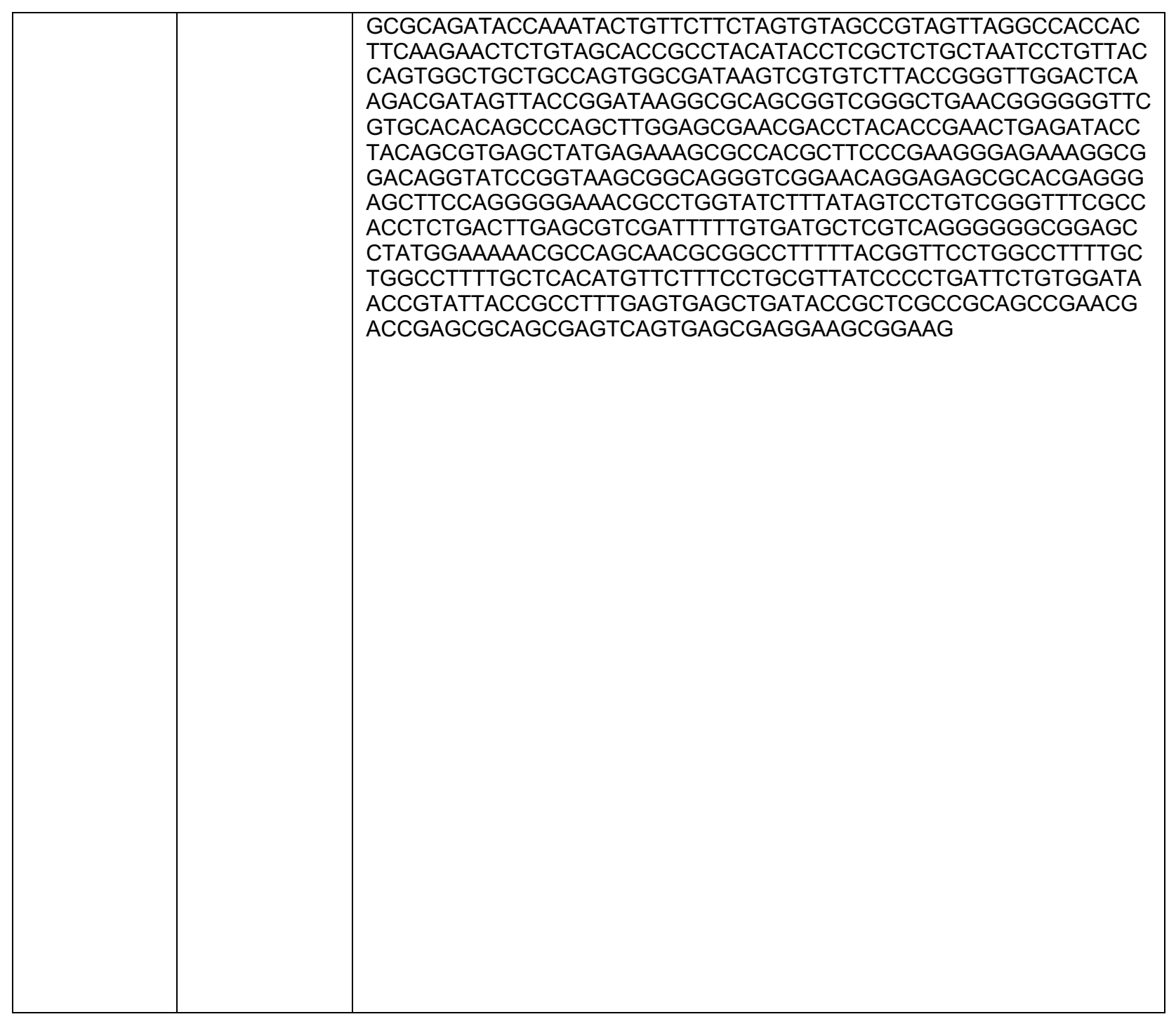




\begin{tabular}{|c|c|c|}
\hline pD3 & $\begin{array}{l}\text { p14_pJLD2 } \\
\text { _Gene2 }\end{array}$ & 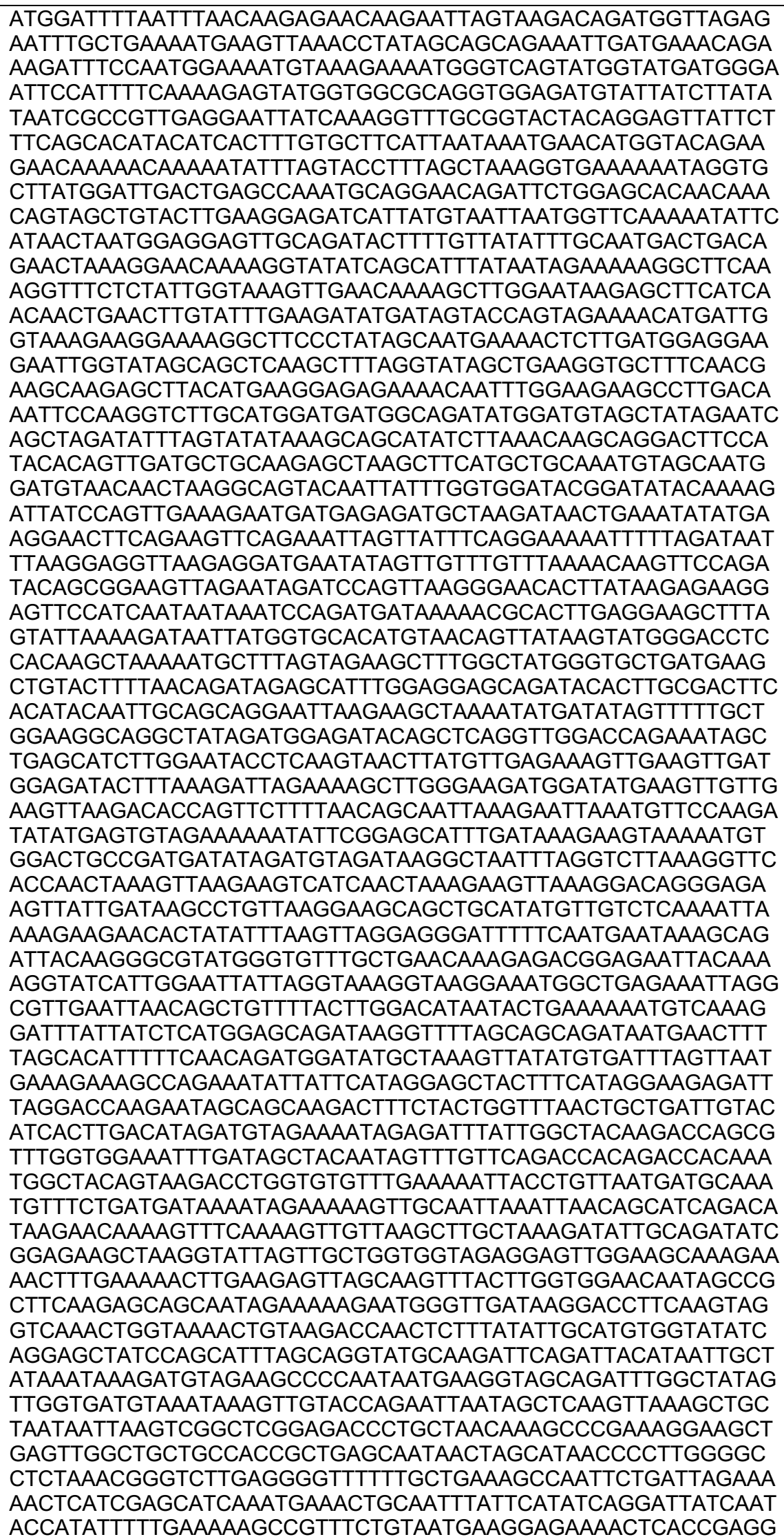 \\
\hline
\end{tabular}




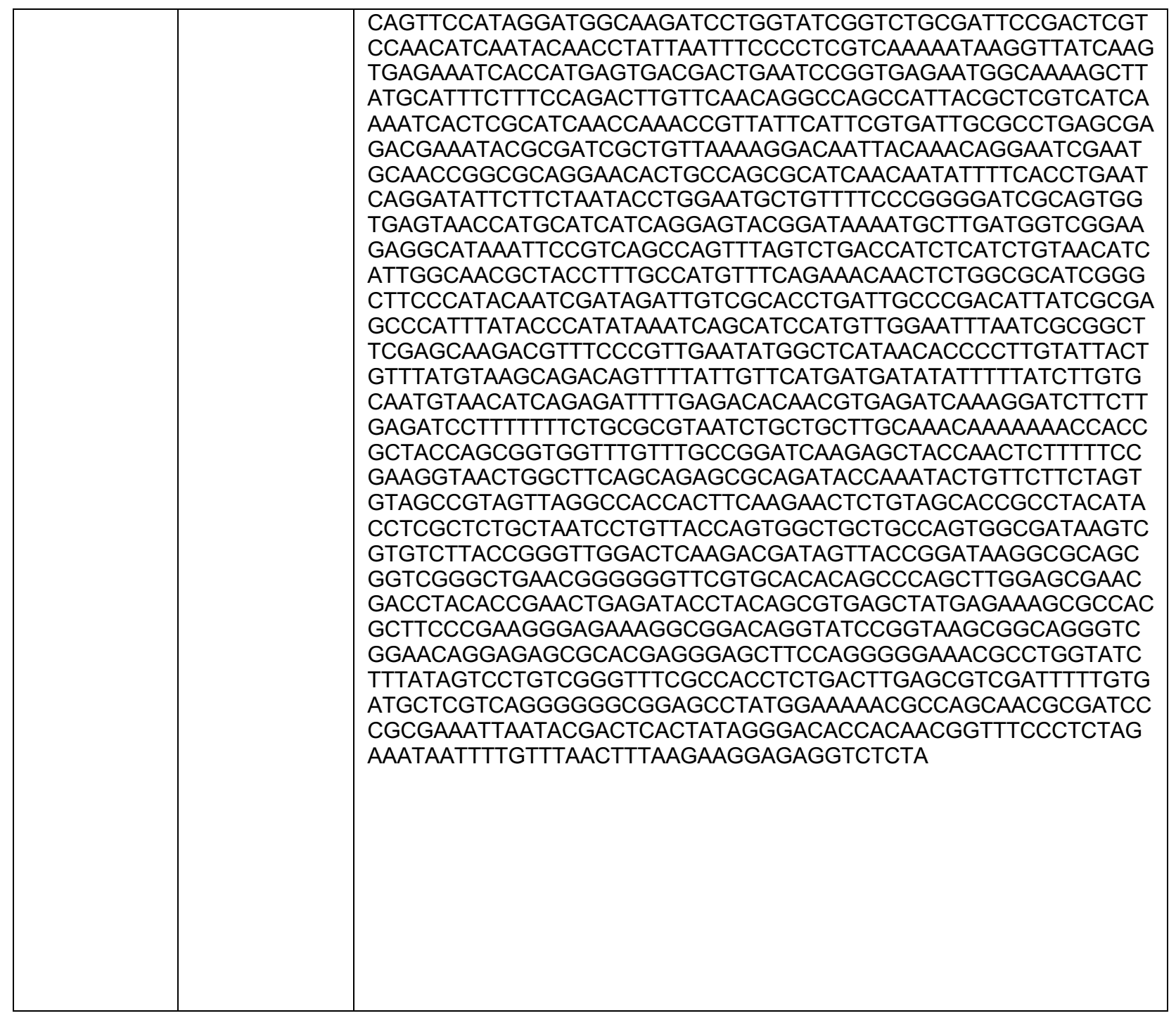




\begin{tabular}{|c|c|c|}
\hline pD4 & $\begin{array}{l}\text { pDN4_GG4 } \\
\text { _Pwl_GG5 }\end{array}$ & 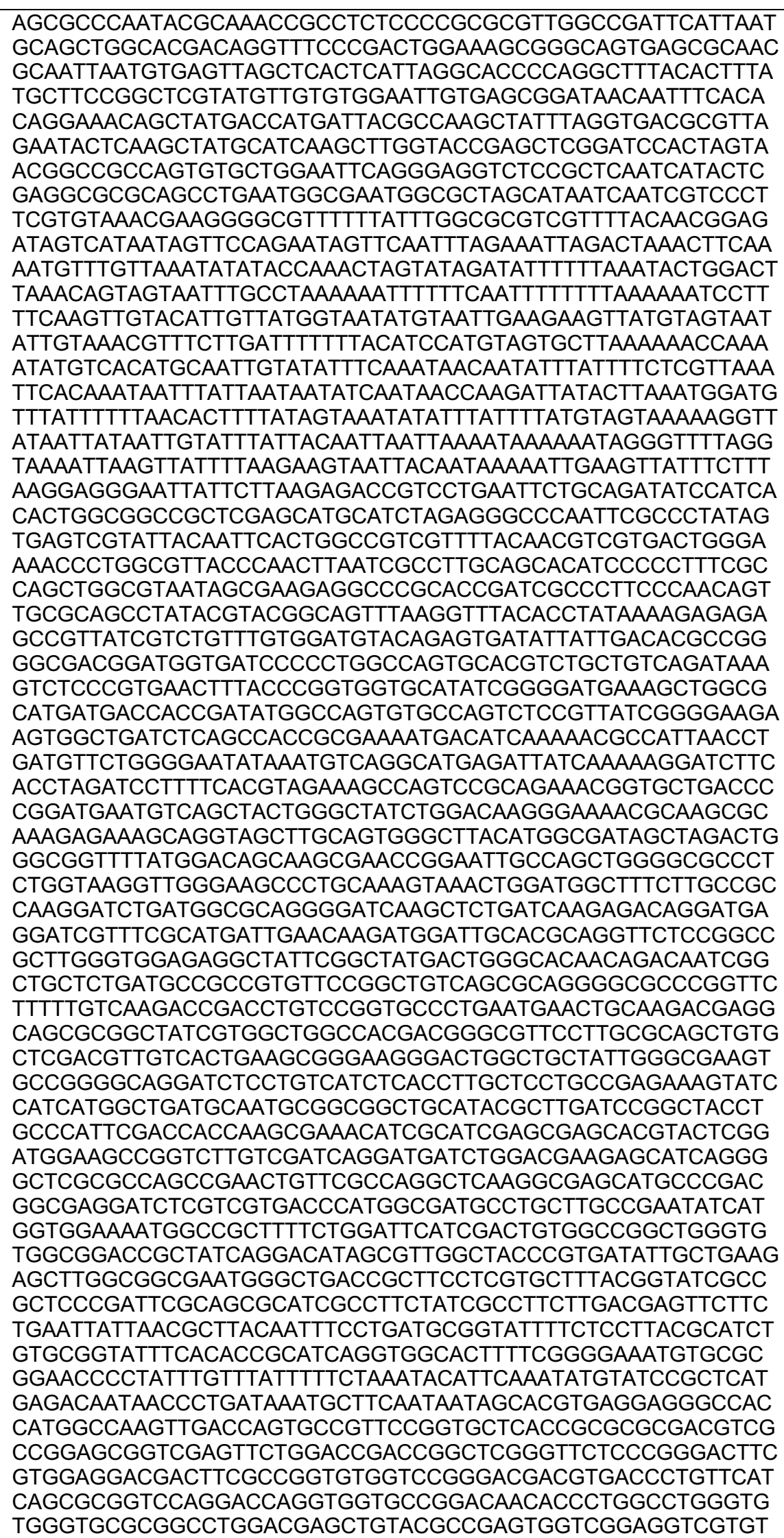 \\
\hline
\end{tabular}




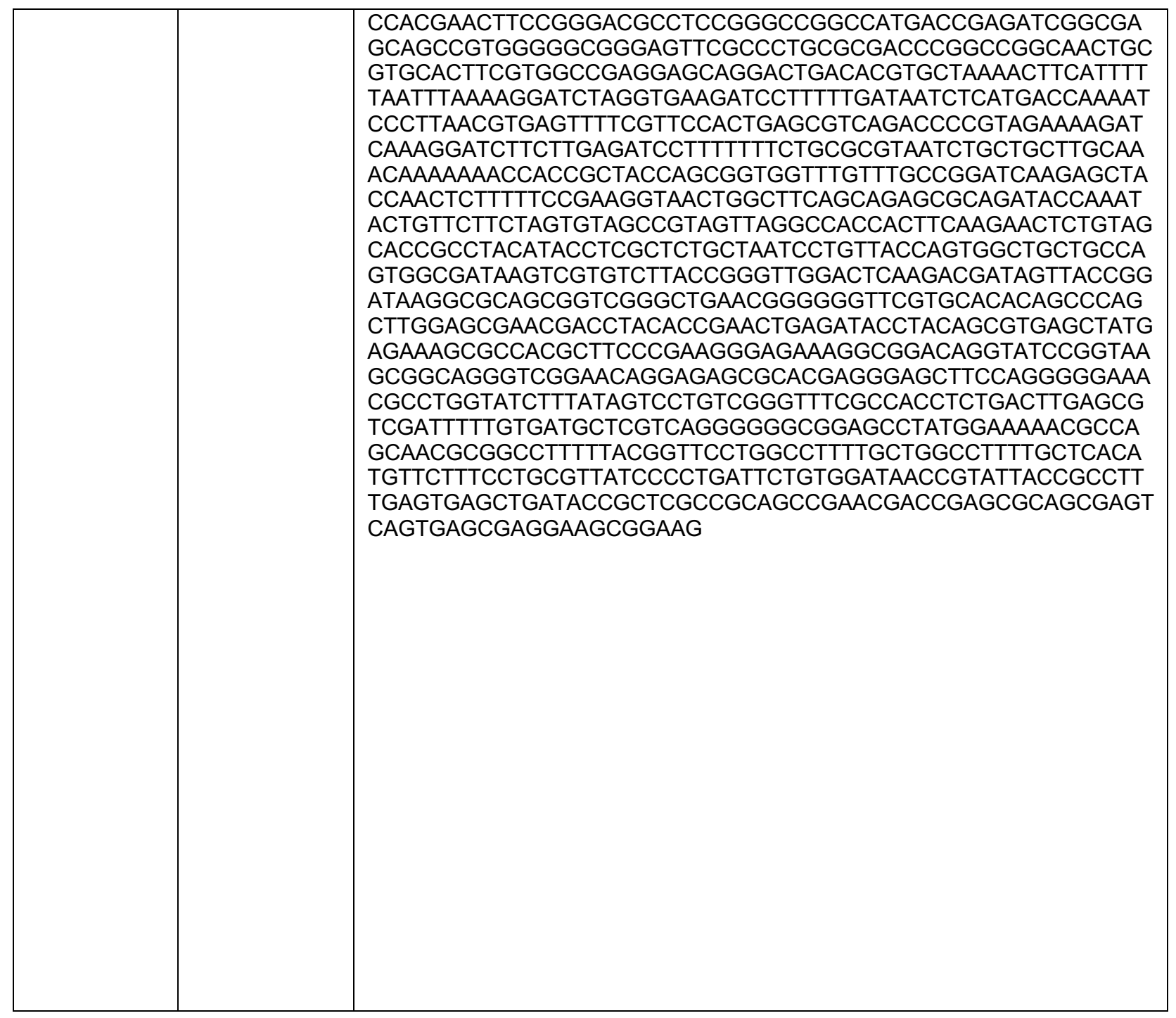




\begin{tabular}{|c|c|c|}
\hline pD5 & $\begin{array}{l}\text { P1_pJLD3_ } \\
\text { Gene3 }\end{array}$ & 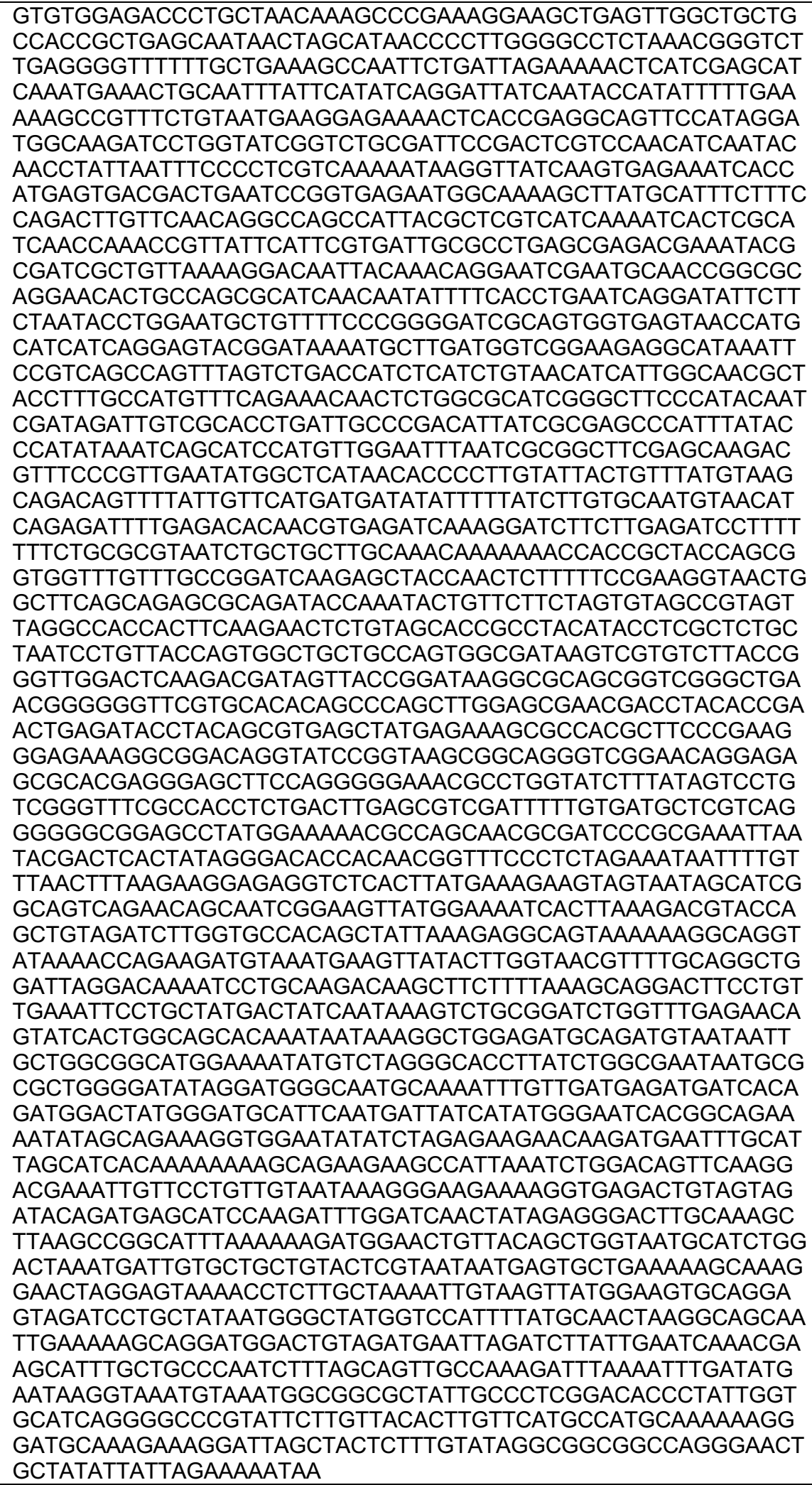 \\
\hline
\end{tabular}


Supplementary Table 2. List of DNA Parts. Terminators, spacers, and promoters are used to construct operons in pCExpress vectors used in this study are listed.

\begin{tabular}{|l|l|}
\hline Terminators & Nucleotide sequence $\mathbf{( 5}^{`}$ to $\left.^{\mathbf{3}} \mathbf{}\right)$ \\
\hline T1 $($ TgyrA) & AAGAAGAATGTGAAAAGCGCAGCTGAAATAGCTGCGCTTTTTTGTGTCATAA \\
\hline T2 (TtyrS) & ATAATCAATCGTCCCTTCGTGTAAACGAAGGGGCGTTTTTTATTT \\
\hline T3 (TpepN) & AATTTATAAATAAAAATCACCTTTTAGAGGTGGTTTTTTTATTTATAAATTA \\
\hline
\end{tabular}

\begin{tabular}{|c|c|}
\hline $\begin{array}{l}\text { Spacers } \\
\text { synthesized } \\
\text { by JGI }\end{array}$ & Nucleotide sequence ( $5^{`}$ to $\left.3^{\prime}\right)$ \\
\hline $\begin{array}{l}\text { pD1 variant } 1 \\
\text { spacer region }\end{array}$ & $\begin{array}{l}\text { TAATACGACTCACTATAGGGACACCACAACGGTTTCCCTCTAGAAATAATTTTGTTTAAC } \\
\text { TTTAAGAAGGAGGTCTCCTCATG }\end{array}$ \\
\hline $\begin{array}{l}\text { pD1 variant } 2 \\
\text { spacer region }\end{array}$ & $\begin{array}{l}\text { TAATACGACTCACTATAGGGACACCACAACGGTTTCCCTCTAGAAATAATTTTGTTTAAC } \\
\text { TTTAAGAAGGAGAGGTCTCTTCATG }\end{array}$ \\
\hline $\begin{array}{l}\text { pD1 variant } 3 \\
\text { spacer region }\end{array}$ & $\begin{array}{l}\text { TAATACGACTCACTATAGGGACACCACAACGGTTTCCCTCTAGAAATAATTTTGTTTTAAC } \\
\text { TTTAAGAAGGAGAAGACCATCATG }\end{array}$ \\
\hline $\begin{array}{l}\text { pD3 variant } 1 \\
\text { spacer region }\end{array}$ & $\begin{array}{l}\text { TAATACGACTCACTATAGGGACACCACAACGGTTTCCCTCTAGAAATAATTTTGTTTAAC } \\
\text { TTTAAGAAGGAGGTCTCTAATG }\end{array}$ \\
\hline $\begin{array}{l}\text { pD3 variant } 2 \\
\text { spacer region }\end{array}$ & $\begin{array}{l}\text { TAATACGACTCACTATAGGGACACCACAACGGTTTCCCTCTAGAAATAATTTTGTTTAAC } \\
\text { TTTAAGAAGGAGAGGTCTCTAATG }\end{array}$ \\
\hline $\begin{array}{l}\text { pD3 variant } 3 \\
\text { spacer region }\end{array}$ & $\begin{array}{l}\text { TAATACGACTCACTATAGGGACACCACAACGGTTTCCCTCTAGAAATAATTTTGTTTAAC } \\
\text { TTTAAGAAGGAGGAAGACATAATG }\end{array}$ \\
\hline $\begin{array}{l}\text { pD5 variant } 1 \\
\text { spacer region }\end{array}$ & $\begin{array}{l}\text { TAATACGACTCACTATAGGGACACCACAACGGTTTCCCTCTAGAAATAATTTTGTTTTAAC } \\
\text { TTTAAGAAGGAGGTCTCACTTATG }\end{array}$ \\
\hline $\begin{array}{l}\text { pD5 variant } 2 \\
\text { spacer region }\end{array}$ & $\begin{array}{l}\text { TAATACGACTCACTATAGGGACACCACAACGGTTTCCCTCTAGAAATAATTTTTGTTTAAC } \\
\text { TTTAAGAAGGAGAGGTCTCACTTATG }\end{array}$ \\
\hline $\begin{array}{l}\text { pD5 variant } 3 \\
\text { spacer region }\end{array}$ & $\begin{array}{l}\text { TAATACGACTCACTATAGGGACACCACAACGGTTTCCCTCTAGAAATAATTTTGTTTAAC } \\
\text { TTTAAGAAGGAGAAGACTACTT } \underline{\text { ATG }}\end{array}$ \\
\hline
\end{tabular}

Green = T7 promoter; Red = Bsal or Bbsl; ATG start codon underlined

\begin{tabular}{|c|c|}
\hline Promoters & Nucleotide sequence ( $5^{\prime}$ to $\left.3^{\prime}\right)$ \\
\hline$f d x$ & $\begin{array}{l}\text { GGCCGCTCACTATCTGCGGAACCTGCCTCCTTATCTGATAAAAAATATTCGCTGCATCTT } \\
\text { TGACTTGTTATTTTCTTTCAAATGCCTAATGGAATTGTGAGCGGATAACAATTAATTATCTT } \\
\text { TTAAAATTATAACAAATGTGATAAAATACAGGGGATGAAACATTATCTAAAAATTAAGGA } \\
\text { GGTGTTA }\end{array}$ \\
\hline pfor & 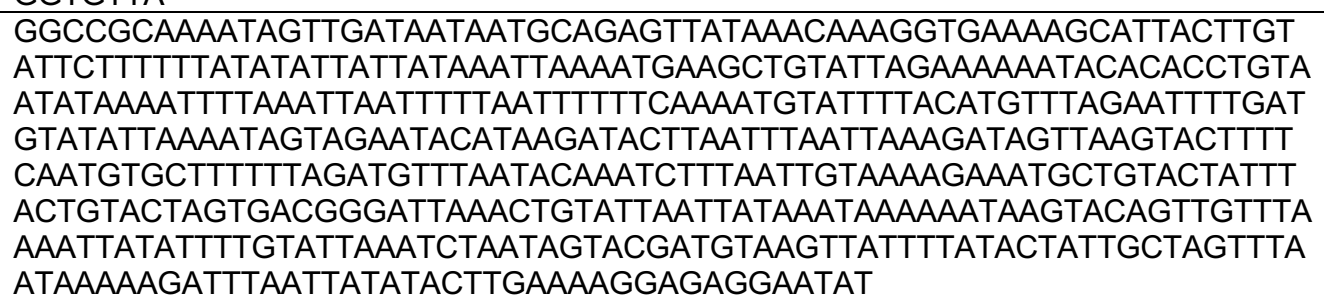 \\
\hline$w l$ & 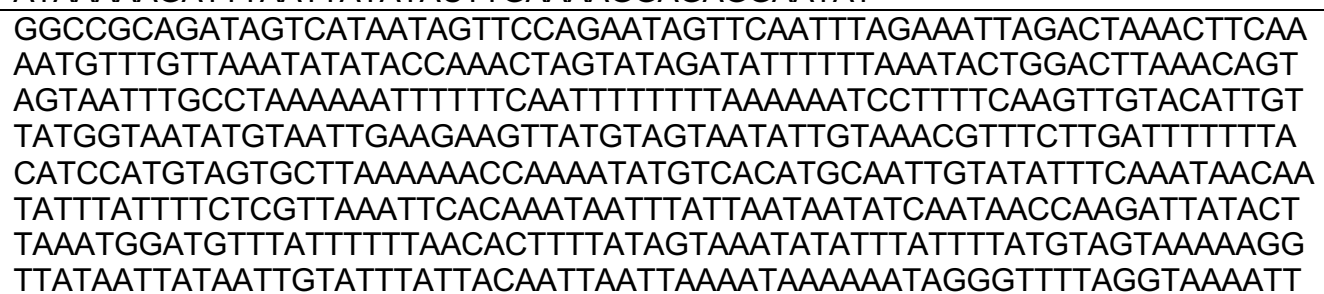 \\
\hline
\end{tabular}


bioRxiv preprint doi: https://doi.org/10.1101/2020.07.22.216267; this version posted July 22, 2020. The copyright holder for this preprint (which was not certified by peer review) is the author/funder. All rights reserved. No reuse allowed without permission.

\begin{tabular}{|c|c|}
\hline & $\begin{array}{l}\text { AAGTTATTTTAAGAAGTAATTACAATAAAAATTGAAGTTATTTCTTTAAGGAGGGAATTATA } \\
\mathrm{T}\end{array}$ \\
\hline pta & 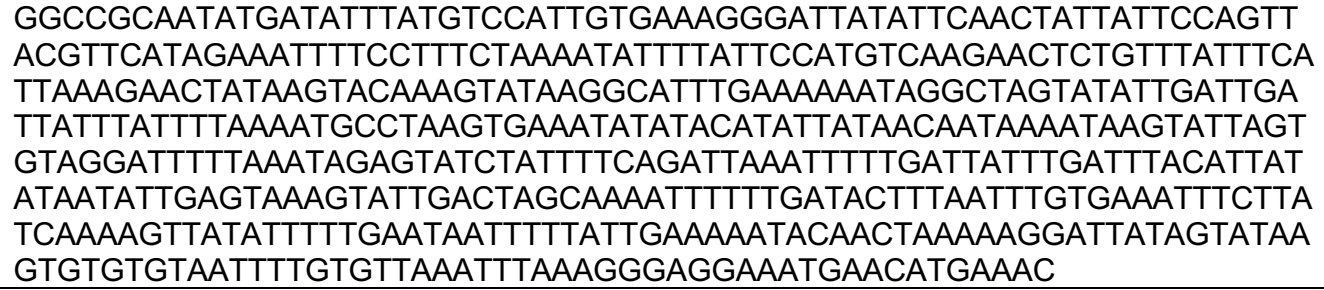 \\
\hline
\end{tabular}


Supplementary Table 3. List of pCExpress and pD2/pD4 variants for assembly versatility. Each variant is listed with name and backbone vector is derived from along with which overhangs, promoter, and terminator is present.

\begin{tabular}{|c|c|c|c|c|c|}
\hline \# & pCExpress vector name & Backbone & GG sites & Promoter & Terminator \\
\hline 1 & pMTL8225_12_Pfer_TpepN & pMTL8225 & OV1, OV2 & $\mathrm{fdx}$ & TpepN \\
\hline 2 & pMTL8225_14_Pfer_TpepN & pMTL8225 & OV1, OV4 & $\mathrm{fdx}$ & TpepN \\
\hline 3 & pMTL8225_56_Pfer_TpepN & pMTL8225 & OV5, OV6 & $f d x$ & TpepN \\
\hline 4 & pMTL8225_36_Pfer_TpepN & pMTL8225 & ov3, ov6 & $\mathrm{fdx}$ & TpepN \\
\hline 5 & pMTL8225_34_Pfer_TpepN & pMTL8225 & OV3, OV4 & $\mathrm{fdx}$ & TpepN \\
\hline 6 & pMTL8225_12_Pwl_TpepN & pMTL8225 & OV1, OV2 & $\mathrm{wl}$ & TpepN \\
\hline 7 & pMTL8225_14_Pwl_TpepN & pMTL8225 & OV1, OV4 & wl & TpepN \\
\hline 8 & pMTL8225_56_Pwl_TpepN & pMTL8225 & OV5, OV6 & $\mathrm{wl}$ & TpepN \\
\hline 9 & pMTL8225_36_Pwl_TpepN & pMTL8225 & ov3, OV6 & $\mathrm{wl}$ & TpepN \\
\hline 10 & pMTL8225_34_Pwl_TpepN & pMTL8225 & OV3, OV4 & $\mathrm{wl}$ & TpepN \\
\hline 11 & pMTL8225_12_Ppfor_TpepN & pMTL8225 & OV1, OV2 & pfor & TpepN \\
\hline 12 & pMTL8225_14_Ppfor_TpepN & pMTL8225 & OV1, OV4 & pfor & TpepN \\
\hline 13 & pMTL8225_56_Ppfor_TpepN & pMTL8225 & OV5, OV6 & pfor & TpepN \\
\hline 14 & pMTL8225_36_Ppfor_TpepN & pMTL8225 & OV3, OV6 & pfor & TpepN \\
\hline 15 & pMTL8225_34_Ppfor_TpepN & pMTL8225 & OV3, OV4 & pfor & TpepN \\
\hline 16 & pMTL8225_12_Ppta_TpepN & pMTL8225 & OV1, OV2 & pta & TpepN \\
\hline 17 & pMTL8225_14_Ppta_TpepN & pMTL8225 & OV1, OV4 & pta & TpepN \\
\hline 18 & pMTL8225_56_Ppta_TpepN & pMTL8225 & OV5, OV6 & pta & TpepN \\
\hline 19 & pMTL8225_36_Ppta_TpepN & pMTL8225 & OV3, OV6 & pta & TpepN \\
\hline 20 & pMTL8225_34_Ppta_TpepN & pMTL8225 & OV3, OV4 & pta & TpepN \\
\hline 21 & pMTL8315_12_Pfer_TpepN & pMTL8315 & OV1, OV2 & $\mathrm{fdx}$ & TpepN \\
\hline 22 & pMTL8315_14_Pfer_TpepN & pMTL8315 & OV1, OV4 & $\mathrm{fdx}$ & TpepN \\
\hline 23 & pMTL8315_56_Pfer_TpepN & pMTL8315 & OV5, OV6 & $\mathrm{fdx}$ & TpepN \\
\hline 24 & pMTL8315_36_Pfer_TpepN & pMTL8315 & OV3, OV6 & $\mathrm{fdx}$ & TpepN \\
\hline 25 & pMTL8315_34_Pfer_TpepN & pMTL8315 & OV3, OV4 & $\mathrm{fdx}$ & TpepN \\
\hline 26 & pMTL8315_12_Pwl_TpepN & pMTL8315 & OV1, OV2 & $\mathrm{wl}$ & TpepN \\
\hline 27 & pMTL8315_14_Pwl_TpepN & pMTL8315 & OV1, OV4 & $\mathrm{wl}$ & TpepN \\
\hline 28 & pMTL8315_56_Pwl_TpepN & pMTL8315 & OV5, OV6 & $\mathrm{wl}$ & TpepN \\
\hline 29 & pMTL8315_36_Pwl_TpepN & pMTL8315 & OV3, OV6 & $\mathrm{wl}$ & TpepN \\
\hline 30 & pMTL8315_34_Pwl_TpepN & pMTL8315 & OV3, OV4 & wl & TpepN \\
\hline 31 & pMTL8315_12_Ppfor_TpepN & pMTL8315 & OV1, OV2 & pfor & TpepN \\
\hline 32 & pMTL8315_14_Ppfor_TpepN & pMTL8315 & OV1, OV4 & pfor & TpepN \\
\hline 33 & pMTL8315_56_Ppfor_TpepN & pMTL8315 & OV5, OV6 & pfor & TpepN \\
\hline 34 & pMTL8315_36_Ppfor_TpepN & pMTL8315 & OV3, OV6 & pfor & TpepN \\
\hline 35 & pMTL8315_34_Ppfor_TpepN & pMTL8315 & OV3, OV4 & pfor & TpepN \\
\hline
\end{tabular}




\begin{tabular}{|l|l|l|l|l|l|}
\hline 36 & pMTL8315_12_Ppta_TpepN & pMTL8315 & OV1, OV2 & pta & TpepN \\
\hline 37 & pMTL8315_14_Ppta_TpepN & pMTL8315 & OV1, OV4 & pta & TpepN \\
\hline 38 & pMTL8315_56_Ppta_TpepN & pMTL8315 & OV5, OV6 & pta & TpepN \\
\hline 39 & pMTL8315_36_Ppta_TpepN & pMTL8315 & OV3, OV6 & pta & TpepN \\
\hline 40 & pMTL8315_34_Ppta_TpepN & pMTL8315 & OV3, OV4 & pta & TpepN \\
\hline 41 & pMTL8225_16_Pwl_TpepN & pMTL8225 & OV1, OV6 & wl & TpepN \\
\hline 42 & pMTL8315_16_Pwl_TpepN & pMTL8315 & OV1, OV6 & wl & TpepN \\
\hline 43 & pMTL8225_16_Pfer_TpepN & pMTL8225 & OV1, OV6 & fdx & TpepN \\
\hline 44 & pMTL8225_16_Pwl_TpepN & pMTL8225 & OV1, OV6 & wl & TpepN \\
\hline 45 & pMTL8225_16_Ppfor_TpepN & pMTL8225 & OV1, OV6 & pfor & TpepN \\
\hline 46 & pMTL8225_16_Ppta_TpepN & pMTL8225 & OV1, OV6 & pta & TpepN \\
\hline 47 & pMTL8315_16_Pfer_TpepN & pMTL8315 & OV1, OV6 & fdx & TpepN \\
\hline 48 & pMTL8315_16_Pwl_TpepN & pMTL8315 & OV1, OV6 & wl & TpepN \\
\hline 49 & pMTL8315_16_Ppfor_TpepN & pMTL8315 & OV1, OV6 & pfor & TpepN \\
\hline 50 & pMTL8315_16_Ppta_TpepN & pMTL8315 & OV1, OV6 & pta & TpepN \\
\hline \multicolumn{7}{|l|}{} & & & & \\
\hline \# & Donor vectors & Backbone & GG sites & Promoter & Terminator \\
\hline 1 & pDN2_GG2_TtyrS_Pfer_GG3 & pD2 & OV2, OV3 & fdx & TtyrS \\
\hline 2 & pDN2_GG2_TtyrS_Pwl_GG3 & pD2 & OV2, OV3 & wl & TtyrS \\
\hline 3 & pDN2_GG2_TtyrS_Ppfor_GG3 & pD2 & OV2, OV3 & pfor & TtyrS \\
\hline 4 & pDN4_GG4_TtyrS_Pfer_GG5 & pD4 & OV4, OV5 & fdx & TtyrS \\
\hline 5 & pDN4_GG4_TtyrS_Pwl_GG5 & pD4 & OV4, OV5 & wl & TtyrS \\
\hline 6 & pDN4_GG4_TtyrS_Ppfor_GG5 & pD4 & OV4, OV5 & pfor & TtyrS \\
\hline 7 & pDN4_GG2_TtyrS_Pfer_GG5 & pD4 & OV4, OV5 & fdx & TtyrS \\
\hline 8 & pDN4_GG2_TtyrS_Pwl_GG5 & pD4 & OV4, OV5 & wl & TtyrS \\
\hline
\end{tabular}


Supplementary Table 4. List of biosynthetic genes used CFE experiments. Genes used are represented by their Genbank accession numbers.

\begin{tabular}{|l|}
\hline Biosynthetic genes (Genbank accession \#) \\
\hline Figure 2 \\
\hline AAA27706.1 \\
\hline AND83415.1 \\
\hline AAA82724.1 \\
\hline WP_100652199.1 \\
\hline AAA23751.1 \\
\hline AAA23750.1 \\
\hline AAA21973.1 \\
\hline WP_077360117.1 \\
\hline AAK80654.1 \\
\hline AAA95971.1 \\
\hline BAA21816.1 \\
\hline BAC44835.1 \\
\hline BAA92740.1 \\
\hline AND85881.1 \\
\hline AAA95967.1 \\
\hline AAA27706.1 \\
\hline
\end{tabular}

\begin{tabular}{|l|}
\hline Supplementary Figure 2 \\
\hline AAM14586.1 \\
\hline AGY75809.1 \\
\hline WP_013240787.1 \\
\hline AGY74649.1 \\
\hline WP_122057754.1 \\
\hline AGY74784.1 \\
\hline AGY76060.1 \\
\hline AGY75962.1 \\
\hline AGY74883.1 \\
\hline AGY74614.1 \\
\hline AGY74782.1 \\
\hline AAA21973.1 \\
\hline AAC38322.1 \\
\hline AAW66853.1 \\
\hline EDK32512.1 \\
\hline AAA95967.1 \\
\hline EDK35681.1 \\
\hline
\end{tabular}


Supplementary Table 5. List of biosynthetic genes used to assess codon usage and assembly efficiency. Genes used are represented by their Genbank accession numbers.

\begin{tabular}{|l|}
\hline Biosynthetic genes (Genbank accession \#) \\
\hline 5Z7R_A \\
\hline AAD31841.1 \\
\hline OOP71501.1 \\
\hline WP_011785966.1 \\
\hline WP_134310305.1 \\
\hline WP_033987601.1 \\
\hline WP_034582189.1 \\
\hline WP_011967672.1 \\
\hline WP_077892378.1 \\
\hline WP_017751917.1 \\
\hline WP_140027439.1 \\
\hline AAB40248.1 \\
\hline AAA95971.1 \\
\hline 4WYR_A \\
\hline WP_012104014.1 \\
\hline WP_024243753.1 \\
\hline 4W61_A \\
\hline 4W61_A (modified) \\
\hline 4N5L_A \\
\hline
\end{tabular}


a

single gene insertion

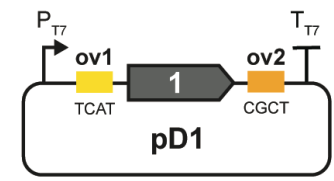

$+$

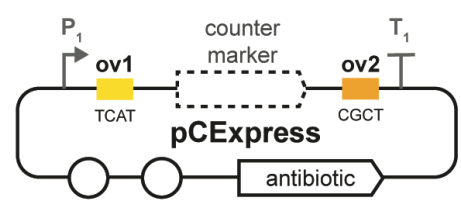

C multi-cistronic insert
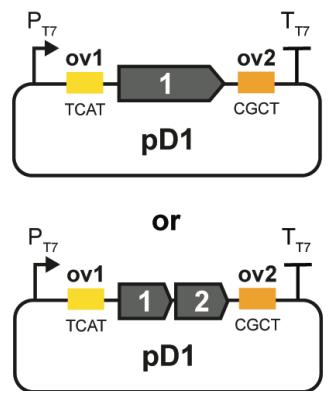

b two-gene insertion

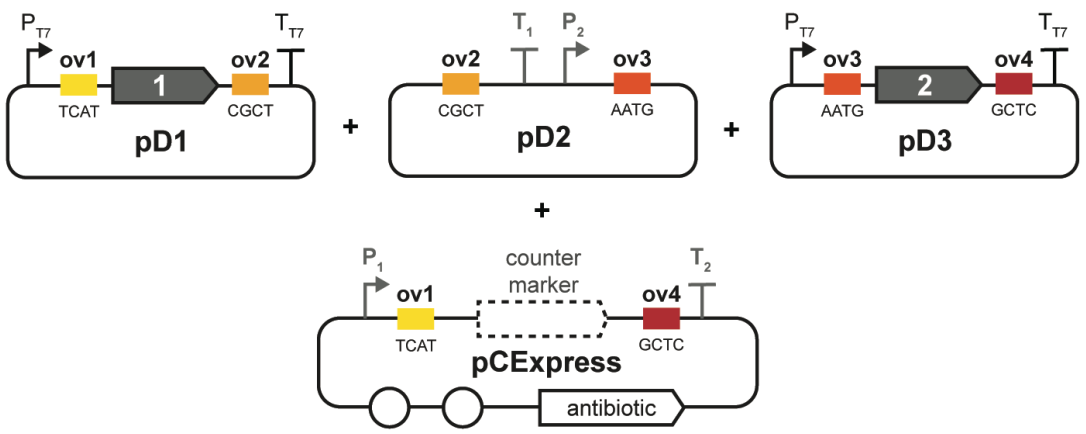

d pCExpress variants

any of the ov1 to ov6 overhangs

promoters from available parts

Pfdx, Ppta, Ppfor, and Pwl

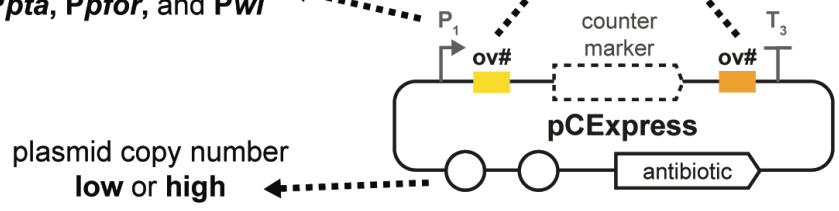

Supplementary Figure 1. A modular 'cell-free to Clostridium' vector system. (A) Two-part assembly for a single gene insertion. (B) Configuration of donor vectors that enables two-gene insertion using defined Ov sites. (C) Modifying pD1 (or pD2, pD3) to hold more than 1 gene allows for complete assembly of more than three genes using the 'Cell-free to Clostridium' vector system. (D) pCExpress can be varied for different assembly types. The key parameters are mentioned here with the full table of variants in Supplementary Table 3. 


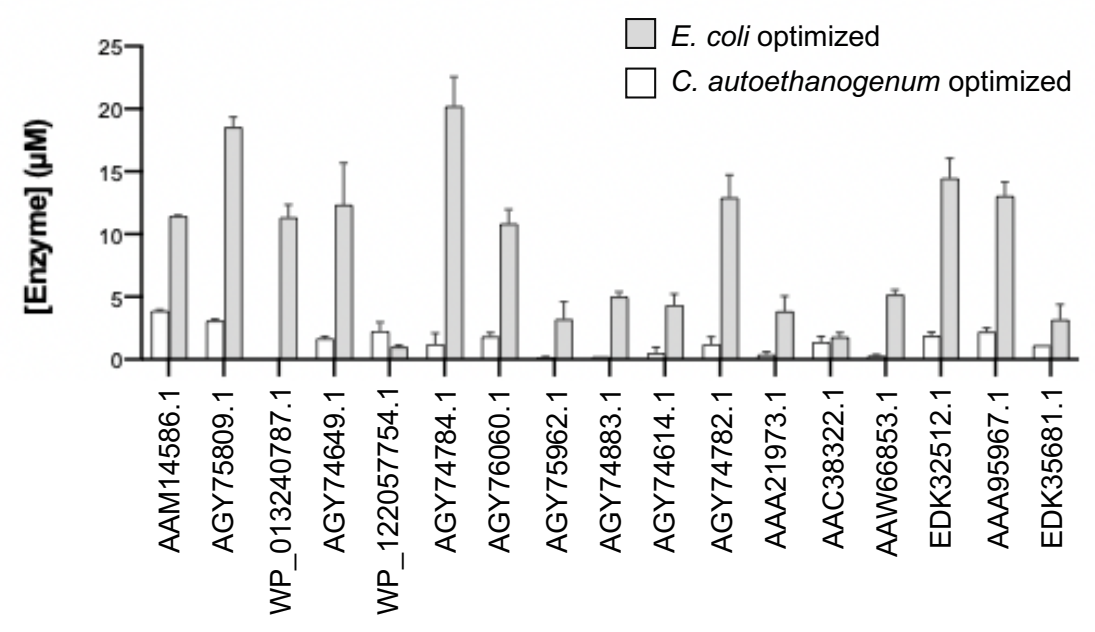

Supplementary Figure 2. Cell-free expression of $E$. coli optimized DNA sequences produce more protein than Clostridium optimized sequences. 17 gene sequences were codon optimized for E. coli and C. autoethanogenum and placed in pJL1. Each was expressed in CFE with $n=2$. Average expression is shown after $20 \mathrm{~h}$ with error bars representing average error. 